\title{
Index for Volume 95
}

AUTHOR AND SUBJECT INDEX. Pages indicating errata are in italic. "A" indicates abstract. Author index for supplement issue is at the end.

Abad, G., 960, 962

Abad, J., 960

Abad, P., 158

Abo, K., 1391

Acaromyces sp., antagonism to plant pathogens, $\mathrm{S} 81$

Acciarri, N., 800

Accotto, G. P., 800

Aceto, S., 206

Acidovorax avenae

-on melon and watermelon, sweatbox method, 962

-on watermelon: biocontrol, 413; blossom infection, S129; honeybee role, S29

Acroptilon repens, biocontrol, Turkey, S14

Actaea racemosa, black root and crown rot, pathogens, S1

Adaskaveg, J. E., 751, 942

Aegilops spp.

$-A$. sharonensis, wheat leaf rust and stem rust, resistance, $\mathrm{S} 165$

- A. tauschii, resistance gene, variation and evolution, $\mathrm{S} 14$

Agar media, sooty blotch and flyspeck fungi, growth, $\mathrm{S} 101$

Agave tequilana

-heart rot, climate effect, 963

-red ring, cause, 964

Agrobacterium spp.: intracellular movement, ssDNA-protein complexes, S135; plant transformation mediated by, $\mathrm{S} 132$

-A. tumefaciens, in walnut, seasonal fluctuation in soil, S55

-A. vitis: biocontrol, mechanism, $\mathrm{S} 22$; on grape, auxin and wood position effect, 362; on grape and tobacco, necrosis and hypersensitivity, 961

Agrostis stolonifera

- dead spot, ascospore release, environment effect, 1356

—dollar spot, fungicide factors, S171

Ahn, I.-P., 1248

Aitken, E. A. B., 489

Ajuga reptans, crown and root rot, Phoma sp., S111

Akimitsu, K., 241

Alam, S. N., 1472

Albugo occidentalis, oospore germination, factors, S152

Alchornea cordifolia, leaf spot, Taphrina cause, S2

Alexander, B., 963

Alfalfa, brown root rot, Minnesota and Wisconsin, S165

Alfalfa mosaic virus, on snap bean, aphidtransmitted, 1405

Algicide, bacterium SG-3, evaluation, S120

Ali, S., 1144

Alioto, D., 420

Allaire, M., 793, 960

Allen, C., 136

Al-Mahruqi, M., 962

Almond

- anthracnose, hemibiotrophic and necrotrophic development, 751

-leaf scorch, genotypes in California, 708

Aloni, R., 362

Al-Saadi, A., 918

Al-Saady, N., 962

Al-Subhi, A., 962

Alternaria spp., phenotypic classification, image analyses, 1021

-A. alternata: on citrus, phylogenetically distinct lineages, 512; on tangerine, resistance, S96; on tangerine and lemon, toxins, 241

-A. arborescens, Agrobacterium tumifaciensmediated transformation, S91

-A. brassicicola, dead zone in model pathosystem, S136

-A. eichhorniae, on waterhyacinth, biocontrol, S95

-A. solani, sensitivity, statewide monitoring, S165

Ameniya, Y., 1072

American Phytopathological Society

_annual meeting abstracts, 960, June suppl.

- annual report, 16

- Caribbean Division abstracts, 2003, S149

-Caribbean Division abstracts, 2004, S153

-Excellence in Extension award, 23

-Excellence in Teaching award, 23

-Fellows, 18

-International Service award, 24

-Lee M. Hutchins award, 22

-Noel T. Keen award, 21

-North Central Division abstracts, 2004, S16

-Northeastern Division abstracts, 2004, S168

-officers, representatives, and committees, 14

-Potomac Division abstracts, 2004, S155

-Potomac Division abstracts, 2005, S158

-Ruth Allen award, 22

- Southern Division abstracts, 2005, S174

- Special sessions (see Special sessions)

-Symposium, Melhus Graduate Student, S127

- Syngenta award, 24

Amerson, H. V., 376

Ammi majus, virus, Florida, S46

Andersen, B., 1021

Andersen, P., 962, 963

Anderson, J., 960

Andrade-Piedra, J. L., 1191, 1200, 1412

Angelonia augustifolis, carmovirus, characterization, S2

Anikster, Y., 53

Annis, S. L., 1174

Aphanomyces euteiches, resistance loci, USA and France, 1287

Aphis gossypii, on melon, virus vector and cDNA library, S58

Apion godmani, on bean, defense response, S152

Apiosporina morbosa, on Prunus spp., genetic diversity and structure, 859

Apple

-bacterial flora, analysis of rRNA genes, S60

- blue mold, control practices, S21

-Brassicaceae seed meal effect, replant soils, S67

- disease management, organic orchards, S43

-fire blight: Agrobacterium-mediated transformation, S3; biocontrol with Thymbra spicata, S116; control with Rhanella aquatilis and sodium-benzoate, S116

-flyspeck: ascospore maturation, S168; management, S21

-foodborne pathogens, biocontrol with bacteria and yeast, S59

- fruit rot, postharvest, S54

-kaolin effect on disease, $\mathrm{S} 8$

-leaf colonization, epiphytes, biocontrol, S68

—patulin accumulation, biocontrol yeast, 1271

- Pythium sp., Brassica seed meal, S20

- scab: epidemic progress, modeling, 1001; predictors, characteristic curve analysis, 679; tree pruning, organic orchards, $\mathrm{S} 43$

- sooty blotch and flyspeck: desiccation and freezing method, viability, S102; expansion, S7; identification with RFLP method, S26;
RFLP patterns and rDNA sequence, S66; warning system, factors, S7

-Stomiopeltis spp., North Carolina, 960

Apricot pseudo-chlorotic leaf spot virus, on stone fruits, 420

Aquatic plants, ecology, fungal pathogens, S120

Arabidopsis spp.: crown gall, metabolic adaptation, S23; defense signaling genes, S170; innate immunity, PAMP-induced, S137; necrotrophic pathogens, transcriptional regulation of gene, S56; resistance and rhizobacterial induction, salicylic acid role, 1349; serine/threonine kinase, Geminivirus, S6; Victoria blight, $L O V$ and let $L I V, \mathrm{~S} 134$

-A. thaliana: cell death, victorin-induced, S101; smut, nonnatural host, 480

Arie, T., 1209

Armillaria spp.

—on daylily, novel disease, S15

-isolates in Wyoming, S10

Ascochyta rabiei, on chickpea, transformation conditions, S111

Asparagus

-decline, management in Netherlands, 962

-Fusarium crown and root rot, outbreak in Quebec, 867

Aspergillus spp.: aflatoxin gene cluster, evolution, S16; aflatoxin and sclerotial production, Mississippi, S1; on seed, oxylipin mediation, S13

-A. flavus: on almond, antagonists in California, S79; on corncob, inoculum source in Texas, $\mathrm{S} 150$; crop rotation effect, Texas, S47; on maize, proteome analysis of resistance, S19; maize seed compounds, secondary metabolism, $\mathrm{S} 44$; on peanut, glucanase and conglutin-like protein, 506

-A. nidulans, histone deacetylases, regulation of metabolism, S96

-A. niger, population dynamics, New York, S95

Aspin, A., 1316

Atencio, F. A., 894

Auclair, A., 964

Avila-Quezada, G., 1341

Avocado, Colletotrichum gloeosporioides, epicatechin metabolism and laccase, 1341

Aytkhozhina, N., 960

Bacillus spp.

-B. licheniformis: Colletotrichum graminicola controlled by, turf, S46; on ornamentals, control in greenhouse, $\mathrm{S} 110$

-B. mojavensis, antifungal inhibitor, identification, S5

-B. subtilis, biocontrol agent, DNA markers, S51

Bailey, D. J., 62

Bailey, W., 964

Bakker, P. A. H. M., 1349

Balci, S., 960

Balci, Y., 960

Balesdent, M. H., 1061

Banana

-Fusarium sp., nematodes suppressed by, S138

-Fusarium wilt, three species, S125

- Sigatoka, Australian population structure, gene flow, 489

Barajas, D., 894

Baranger, A., 1287

Barbetti, M. J., 1061

Bardin, M., 556

Barker, I., 1462

Barker, K. R., 186

Barley 
- powdery mildew, $\mathrm{R}$ genes, transcription patterns, S122

-Septoria speckled leaf blotch, resistance and molecular mapping, STS markers, S58

-stripe rust: molecular mapping, 884; resistance genes, molecular mapping, 427

Barley mild mosaic virus, vector transmission, S3

Barley stripe mosaic virus, white leaf strain, S27

Barley yellow dwarf virus

- aphid transmission, genetics, S15

-MAV-like serotypes, Alaska, S89

- on winter wheat, aphid relation, S45

Bausher, M. G., 381

Bean, anthracnose: and abiotic stress, varibility, S30; circadian clock and genes, profile expression, S31

Bean common mosaic necrosis virus: Bean common mosaic virus comparison, genotyping for resistance alleles, 499; recombinants, 1037

Bean pod mottle virus, on soybean:

- cultivar response, $\mathrm{S} 118$

_inoculation method and yield effect, S164

Beet curly top virus, on sugar beet, ratings and yield, S100

Begomovirus

- on malvaceous and weed species, Mexico, S42

-on Phaseolus vulgaris, bean leaf crumple disease, 819

-on tomato resistance screening and whitefly transmission, 1472; sequence analysis, Nile and

Mediterranean Basins, 549

-whitefly relation, Guatemala, S151

Bejarano, E. R., 1089

Bélanger, R. R., 114

Benhamou, N., 114

Bennett, R. S., 300

Bergelson, J., 961

Bergeron, M.-J., 793

Bergstrom, G. C., 300, 472

Bermudagrass, forage, fungicide in Mississippi, S84

Bernier, L., 608, 960

Berry, S. T., 664

Bhatia, A., 512

Biofungicides, compost tea, pumpkin and tomato diseases, $\mathrm{S} 171$

Bioinformatics, molecular breeder tool kit, S139

Biological control

-bacteria for Acidovorax avenae on watermelon, 413

-Botrytis cinerea and Ulocladium atrum, models, S52

- cotton leaf spot and damping-off, binucleate Rhizoctonia, 1030

-Cryptococcus laurentii, silicon effect, 69

-Cryptococcus nodaensis for Fusarium head blight, wheat, 626

- cucumber root disease, suppression by growth on rockwool, 808

- Lysobacter enzymogenes for Bipolaris leaf spot of fescue and Pythium damping-off of sugar beet, 701

- peanut late leaf spot, bacteria, chitinolysis, 1157

-Pochonia chlamydosporia for Rotylenchulus reniformis on cotton, 890

- pseudomonads, potential in corn and soybean fields, 715

-Pseudomonas spp.: biogeography, S145; genetic engineering, S145; genomic sequence, S144; history and the future, S145; integrated control, S145; molecular communication, S145; systemic resistance, $\mathrm{S} 145$

-Rhizoctonia, binucleate isolate, Rhizoctoniainfected beans, 345

-seedling damping-off by compost, container media, 306

- streptomycetes, antibiotic in Rio Grande Valley soil, S66
- transgenic enhancement, S126

-Trichoderma asperellum for cucumber diseases, 76

-Ulocladium atrum for Botrytis cinerea on cyclamen, 439

- virulence and dissemination of agents enhanced, S126

—weeds, hemibiotrophic fungus for, S155

Biosecurity

—APS contributions, S147

—current policies and research, S147

— priorities in plant pathology, S147

-USA crop vulnerability to pathogens, S147

—visa issues, students and exchange scientists, S148

Biotechnology

-crop improvement, gene sources, S132

- plant pathology contributions, S132

Bipolaris spp., on forage bermudagrass in Mississippi, 1183

-B. sorokiniana: on tall fescue, biocontrol with Lysobacter enzymogenes, 701; on wheat, cell wall apposition, cover photo, May; on wheat, defense mechanisms, model genotypes, 528

Blackberry, viruses of, mixed infections, S101

Blueberry

—anthracnose, volatiles as markers, S84

- crown gall, Argentina, S82

-Monilinia vaccinii-corymbosi, pseudosclerotial development, S93

-mummy berry disease, yield effect, bud phenology, 1174

- Septoria and anthracnose, fungicides, S13

-Septoria leaf spot: leaf age, defoliation, and yield, S128; survival analysis, 108

Blumeria graminis, on wheat, diversity in Iran, S87

Blumeriella jaapii

-on cherry, fungicides, Michigan, S85

-fungicide resistance, 14alpha-demethylase, S63

Bockus, W., 961

Boehm, M. J., 626

Boissot, N., 600

Boonham, N., 1462

Bootten, T., 963

Borgemeister, C., 659

Borst, R., 962

Bosco, A., 1316

Bosselut, N., 1151

Botanga, C. J., 1166

Botryosphaeria spp., on sweetgum, irrigation and fertilization study effect, S99

Botrytis cinerea

-on Arabidopsis, defense response genetics, S136

-on cyclamen, Ulocladium atrum as biocontrol, 439

-on grape: fungicide and spray timing, S118; population dynamics, saprotrophy and virulence, 692

- on lisianthus, resistance, S110

- phytotoxic proteins and pectinases, S136

- on pomegranate, postharvest treatments, S79

-yeast antagonism, carbon source, S14

Boudon, S., 1081

Brandonisio, A., 339

Brassica napus (see also Canola and Rapeseed)

- Sclerotinia stem rot, resistance in greenhouse and field, S53

- Streptomyces, Rhizoctonia root rot suppressed by, $\mathrm{S} 20$

Braun, E., 961

Brennaria rubrifaciens, on walnut, detection, S67

Brizzard, G., 158

Brome mosaic virus, on wheat, Alabama, S45

Brown, J. K. (Ariz.), 549, 962, 1217

Brown, J. K. M. (UK), 664

Bruin, N., 962

Buchner, R. P., 1132

Buimer, M., 962
Burkholderia spp., on rice, panicle blight, S73

-B. cenocepacia, type IV secretion system, PHDC lineage, S28

-B. cepacia, on onion, diversity and pathogenicity, S47

Burpee, L. L., 463

Burr, T. J., 362, 961, 962

Bursaphelenchus xylophilus

- on Japanese black pine, xylem cavitation, magnetic resonance microscopy, 737

- on pine, PCR for detection, 566

Butler, D. R., 1301

Cabrefiga, J., 1430

Cacao (see also Theobroma cacao)

-biological control, bacterial endophytes as agents, S157

—black pod rot: biocontrol agents, S171; endophytes for biocontrol, S69

—integrated pest management, status, S159

Cai, G., 257

Calla lily chlorotic spot virus, in Watermelon silver mottle virus serogroup, 1482

Calonnec, A., 1453

Camellia japonica, Phytophthora sp., fungicides, S100

Campaña, A., 85

Candresse, T., 420, 617

Canola (see also Brassica napus and Rapeseed)

- green manure, with Indian mustard, soilborne pathogens, $\mathrm{S} 7$

Cao, A. X., 566

Cao, T., 581

Capsicum annuum

- Cucumber mosaic virus, virus titer, S72

-Pythium aphanidermatum, carbon gain, 354

-root-knot nematode, resistance and histology, phenolics, 158

-Tomato yellow leaf curl virus, dead-end host, 1089

—wilt, spatial dynamic, S149

Capsicum chlorosis virus, on tomato, new vector in Thailand, 659

Caputo, L., 1271

Caranta, C., 227

Carica papaya, phytoplasma, Mexico, S74

Carix blanda, resistance genes, $\mathrm{S} 102$

Carlavirus potato virus $S$, Potexvirus potato $X$ comparison, potato in Australia, S128

Carlier, J., 489

Carpenter-Boggs, L., 512

Carris, L. M., 512

Carrot

-Alternaria and Cercospora leaf blights, New York, S169

—foliar diseases, IPM strategies, S89

-leaf blight, crop rotation effect, S169

-purple leaf, spiroplasma and phytoplasma association, Washington, S57

Cassava

- mosaic diseases, management in South Africa, $\mathrm{S} 72$

—root rot, Fusarium spp., Africa, S6

Cassava mosaic virus, in Africa, livelihood effect, S129

Castillo, P., 368

Castoria, R., 1271

Castroviejo, M., 541

Cauliflower, bacterial disease, Mexico, S32

Celery, late blight, fungicides and disease prediction, S161

Ceratocystis spp.

-C. fagacearum: continental and intercontinental spread, S127; on oak, nitidulid beetle relation, Texas, S41; origin and genetic diversity, S126; sap beetle vector, S161; spatial patterns, S127; systemic chemical control, S127; vectors, S127

-C. fimbriata, on Araceae, pathogenicity, variation, dispersal, 316 
Ceratothripoides claratris, Capsicum chlorosis virus vector, on tomato in Thailand, 659

Cercospora sp., on Japanese tree lilac: identification, S25; temperature optima, S25

-C. apii, morphotype, distinct species, 951

-C. beticola, on sugar beet: disease-monitoring thresholds, factors, 269; fungicide management, S53

-C. kikuchii, on soybean: laboratory assay, S174; vegetative compatibility groups, 257

-C. zeae-maydis, on maize, model, artificial neural network, regression, 388

Cercosporidium personatum, on peanut: microarray analysis, S37; transcripts in disease response, 381

Cereal yellow dwarf virus, virus movement and aphid feeding restriction, $\mathrm{S} 123$

Cereals, estimating rust losses, S132

Chacón, M. G., 1412

Chartrain, L., 664

Chatterton, S., 354

Chen, C.-C., 1482

Chen, J., 708

Chen, L.-F., 533

Chen, T.-C., 1482

Chen, X. M., 427, 884

Cherry

- fungicides, phytotoxicity and yield, S43

-leaf spot: and coryneum, resistance, S90; fungicides for control, S68

- little leaf, phytoplasma, S106

Cherry, B., 965

Chestnut

—blight, hypovirulent isolates, S156

- canker, hypovirus, S155

Chet, I., 76

Chiang, C.-H., 533

Chili veinal mottle virus, on pepper, molecular and pathotype diversity, serology, 227

Chipps, T. J., 292

Chiroleu, F., 600

Chu, F.-H., 1482

Ciancio, A., 262

Cicer arietinum

-Ascochyta blight, pseudothecia and ascospore dispersal, Mediterranean, 1279

-resistance evaluation, Nebraska, S40

—root-knot nematode, feeding site induced, 368

-wilt, variability in Mexico, S151

Cilas, C., 1301

Ciliento, R., 206

Circulifer haematoceps, Spiroplasma citri vector lectin binding, 541

\section{Citrus}

- anthracnose and stem-end rot, fungicide before and after harvest, S116

-bacterial canker and bacterial spot, enumeration and discrimination of strain, PCR, 1333

-bacterial spot, bacteriophages, S6

-black rot, phylogenetically distinct lineages, 512

- canker: cultivar transformation, resistance, S35; dispersal plume and wind speed, S12; eradication compared with plum pox program, conflicting agendas, S129; extension education program, S17; hurricane and storm effect on dispersal, S36; image analysis, S11; key lime susceptibility, S154

-ethylene for color change, Texas, S97

-Ideovirus, detection by subtraction hybridization, S24

-leaf blotch, dweet mottle disease, virus cause, S39

—nematode, management in Texas, S97

- Phytophthora and root pest interaction, management, S140

—phytoplasmas, S86

- sudden death, Marafivirus, S24

—viruses, multiplex PCR assay, S90
Citrus jambhiri, Alternaria leaf spot, toxins, 241

Citrus psorosis virus, coat protein gene, transgenic plants, S52

Citrus reticulata, brown spot, toxins, 241

Citrus tristeza virus

-aphid transmissibility, amino acid sequence, S91

— genetic marker analysis, genotypes, 909

- genome analysis, resequencing microarrays, S114

-on grapefruit, resistance, S71

- polymorphism, India isolates, S91

- transmission variability in Florida, aphid, S58

Civerolo, E. L., 708

Cladosporium sp., on yellow starthistle, biocontrol, S155

-C. carpophilum, on nectarine, fungicides, S171

Clavibacter michiganensis, on tomato:

-PCR detection, S50

-QPCR amplification pattern, S107

Claviceps purpurea, on Spartina alterniflora, biocontrol agent, S29

Clitoria ternatea, disease controlled by antifungal protein, S52

Closteroviridae, on Mentha spp., characterization, 1043

Cochliobolus spp.

-C. heterostrophus, virulence, S134

-C. miyabeanus, on rice: cultivar symptoms, cover photo, November; defense mechanisms, 1248

-C. sativus: on barley, virulence genetics, S17; on wheat, epidemiology in Himalayas, 248

Coconut, lethal yellowing, characterization in Cuba, S153

Cocos nucifera, DNA/RNA ratios in plants, S152

Coffea arabica, stem canker, advanced progenies, $\mathrm{S} 150$

Coffee, wilt, update in Africa, S125

Colletotrichum spp., on chili pepper, salicylic acid, S18

-C. acutatum: on almond, hemibiotrophic and necrotrophic development, 751; on blueberry, infection timing, S24; on blueberry, winter reservoir, S155; on strawberry, pyraclostrobin for control, S82; on strawberrry, resistance inheritance, 405

-C. gloeosporioides: on avocado, laccase and epicatechin, metabolism, 1341; on mango, ozone for control, S149; on northern jointvetch, strain competition, $\mathrm{S} 25$

-C. graminicola: benzimidazole resistance, California isolates, S113; on corn, growth in tissue, S107; on corn, root infection, 965; on maize, biotrophy to necrotrophy, S80; on maize, development in resistant tissues, S72

$-C$. sublineolum, on sorghum, pathotypes in Arkansas, S71

Colocasia esculenta, sustainable agriculture, Hawaii, S106

Colombian datura virus, on Brugmansia spp., Florida, S2

Colvin, J., 1472

Compost

— particle size effect on soil pathogens, S62

- soil properties and root rot suppression, organic amendments, S165

Conn, K. L., 28

Container media, compost sources, damping-off suppression, 306

Cools, H. J., 933

Coral reef, marine host-pathogen interactions, S120

Cork, A., 1472

Corn (see also Maize)

-Fusarium spp. and fumonisin, South Africa, S88

—leaf blight, fungicide in Georgia, S175

- seedling diseases, azoxystrobin and fludioxonil evaluation, Illinois, S166

- Stewart's disease, prediction with Iowa State Model, S165

-sweet: beetle damage, S70; Northern corn leaf blight, race 1 resistance, 85 ; rust, initial inoculum, S172

Corn and soybean, pseudomonads, biocontrol potential, 715

Cornus florida (see als Dogwood)

-Colletotrichum spp., molecular analysis, 964

-disease resistance, gene analogs, S95

- powdery mildew, yeast as biocontrol, S72

Corrado, G., 206

Corylus avellana, bacterial twig dieback, 1316

Corynespora cassiicola

—bioherbicide for Stachytarpheta jamaicensis, S93

—on soybean, glyphosate relation, ragweed, S45

Cotton

-damping-off: biocontrol, S36; chemical and biological seed treatment, $\mathrm{S} 44$

-reniform nematode, Pochonia chlamydosporia for control, 890

-Rhizoctonia damping-off and Alternaria leaf spot, biocontrol in benzothiadiazole, 1030

-seedling disease, soil factors and cropping history, S94

- seed-rotting bacteria, Texas stink bugs, S8

—wilt, strain diversity in Ivory Coast, 1391

Cover photo

-Bipolaris sorokiniana, on wheat, cell wall apposition, May

-Capsicum annuum, Meloidogyne spp., root inoculation, February

- Crinipellis perniciosa, on Theobroma cacao, interaction, January

-Gibberella zeae, on wheat, strain differences, July

-Meloidogyne artiellia, on chickpea roots, April

-Mentha sp., disease symptoms, September

-Phaseolus coccineus, white mold, breeding nursery in Oregon, March

- Phytophthora sp., on cranberry, sporangia in oospores, October

- Plasmopara viticola sporulating on grape, December

—rice, Magnaporthe grisea strains, November

-Tobacco curly shoot virus, symptoms, August

-Xylella fastidiosa, on almond, leaf scorch, June

Cowger, C., 972, 1363

Coyne, C. J., 1287

Cranberry

- field and storage rot, Massachusetts, S17

— fruit rot, inoculum sources, S78

-root and runner rot, Phytophthora spp., New Jersey, 1237

—upright dieback, histology, S17

Creamer, R., 964

Creasap, J. E., 362

Crinipellis perniciosa

-on cacao: interaction, 101; relation with black pod, 1301

-on Theobroma cacao, interaction, cover photo, January

Crippen, D., 890

Cronartium spp.

-C. quercuum, on loblolly pine, resistance gene Fr1, 376

-C. ribicola: on Pedicularis and Castilleja spp., North America, S116; on white pine, chitinase and canker growth, 284; on white pine, molecular epidemiology, 793

Crop loss assessment, wheat scab, meta-analysis, 1225

Crous, P. W., 951

Cryphonectria parasitica, on chestnut:

-mating in natural populations, S171

- second reovirus, $\mathrm{S} 42$

Cryptococcus spp. 
-C. laurentii, on sweet cherry, biocontrol and silicon activity, 69

-C. nodaensis: biocontrol for Fusarium head blight, on wheat, 626; biocontrol agent for Fusarium head blight, S26; on wheat, combination with chemical, S117; on wheat, Fusarium head blight effect, choline, S93

Cuadrado, I. M., 1089

Cubero, J., 1333

Cucumber

- downy mildew, thermography, 233

-resistance, induced by disruption of flavonoid pathway, 114

-root and crown rot, rockwool medium effect, 808

- systemic resistance, jasmonic acid/ethylene signaling pathway, 76

Cucumber mosaic virus

- on snap bean: aphid-transmission, 1405; aphid vectors, S34

- on tomato, ant-aphid mutualism, S21

-virulence and host adaptation, analysis, 827

Cucumis melo (see also Melon and Watermelon)

-Monosporascus, resistance, S22

Cucurbits

- Acidovorax avenae and Didymella bryoniae, detection using real-time PCR, S29

-bacterial fruit blotch, peroxyacetic acid and copper, irigation water, S44

- disease development, Lucid key, S44

- Papaya ringspot virus, engineered strains, 533

— powdery mildew, management, S68

Cucurbit yellow stunting disorder virus, on melon, resistance, $\mathrm{S} 80$

Cullen, D. W., 1462

Curtobacterium flaccumfaciens, on cucurbit, re emergence in Nebraska, S40

Curvularia spp., on forage bermudagrass in Mississippi, 1183

Cylindrocarpon destructans, on ginseng, root rot factors, 1381

Cylindrocladium parasiticum, on peanut, population structure, S17

Cynodon dactylon, variation in Bipolaris, Curvularia, and Exserohilum, 1183

D’Addabbo, T., 339

Dahlia mosaic virus, detection, molecular characterization, S79

Dallot, S., 1453

Dang, P., 381

Datnoff, L. E., 966

Daugrois, J. H., 220

Davidson, J. M., 587

de Bruijn, F. J., 1098

De Cicco, V., 1271

De Curtis, F., 1271

Dehne, H.-W., 233

DeJong, T. M., 581

Delli Bovi, P., 206

Delphinium, powdery mildew:

-environment factors, S110

— fungicides, S154

Demangeat, G., 1151

DeMason, C. A., 942

Denoyes-Rothan, B., 405

dePauw, R. M., 144

Dernoeden, P. H., 1356

Diagnostics, DNA array, disease management, 1374

Diaporthe citri, on citrus, colonization and survival, S71

Díaz, J., 1423

Díaz-Pendón, J. A., 840

Díaz-Ruíz, J. R., 894

Didymella rabiei, on chickpea, pseudothecia and ascospore dispersal, Mediterranean, 1279

Diéguez-Uribeondo, J., 751

Dillard, H. R., 1405
Di Maro, A., 206

Dinoor, A., 1279

Dintinger, J., 600

Diplodia pinea, on jack pine, persistence in nurseries, S99

Disease control, radio frequency, red oak and yellow pine, $\mathrm{S} 104$

Disease forecasting (see also Model)

-BLITECAST and TomFAST, timely dissemination, S170

-MARYGLYT and Cougarblight, for fire blight, comparison, $\mathrm{S} 156$

Disease loss, use by extension plant pathologists, S131

Disease management (see Management)

Disease transmission, flower-infecting fungi, comparative analysis, S75

Ditylenchus dipsaci, phylogeny, spacer-rDNA, 1308

Djian-Caporalino, C., 158

Dogimont, C., 556

Dogwood (see also Cornus florida)

- powdery mildew, resistance components, S60

Dong, K., 186

Dracaena spp., badnaviruses, New Zealand, S76

Driever, G. F., 926

Druffel, K. L., 1037

Dubos, B., 692

Duffié, L., 964

Dulcamara mottle virus, tRNA-like structure lacking, S106

Dulucq, M. J., 420, 617

Duncan, R. A., 581

Duveiller, E., 248

Echida, R., 965

Edel-Hermann, V., 1391

Edema, R., 715

Eggers, J., 960

Ekramoddoullah, A. K. M., 284

El-Allaf, S. M., 1049

Elliott, D., 963

Endophytes

-anti-pathogen effects, tropical plants, S138

— as biocontrol, S138

—bacterial, biocontrol effect, S138

—clavicipitaceous, resistance enhanced, S138

Epidemiology

- assessment dates, permutation tests, lattice, 1453

-binary, size significance, S169

-field sampling, portable tower, S12

-host diversity effect, mixture theory, S98, 328

-New Zealand, prevention, S130

-quadrat variation and size, clump size ratio, 452

Errata

—vol. 93, no. 3 (2003), 1363

—vol. 94, no. 6 (suppl.) (2004), S173

—vol. 94, no. 12 (2004), 124

—vol. 95, no. 6 (Suppl.) (2005), 960, 966, 1112

—vol. 95, no. 9 (2005), 1363

Erwinia spp.: host range, hybridization, S104; potato, detection in tubers in Egypt, S95

-E. amylovora: blossom blight management, evaluation, S110; disease-dose and time relations, 1430; forecasting program, S24; pear and apple flowers, epiphyte, S128

-E. betavasculorum, colony type derivatives, S72

-E. carotovora, aluminum chloride and sodium metabisulfite effect, S173

-E. chrysanthemi: biofilm formation, genes and virulence, S133; efflux pumps and resistance, S133; genome, evolution, S133; IAA biosynthetic pathway, S115; multi-drug resistance regulation, S86; pleiotropic phenotypes, disruption, S117; population behavior analysis, S82; virulence factors, enzymes and iron, S133; virulence gene, discovery, S133

Erysiphe spp.
-E. necator, on grape, detection in Washington, S36

-E. pulchra, on dogwood, infection process, S61

Esker, P., 648

Esmenjaud, D., 1151

Eutypella vitis, on grape, Michigan, S51

Exserohilum spp.

-E. rostratum, on forage bermudagrass in Mississippi, 1183

-E. turcicum, on sweet corn, resistance to race 1 , 85

Extension

-Africa, Andean America, and Asia, S146

-culture, communication, and conflict, S146

— global challenges, S146

—international, training, S147

-Middle East and Midwest, S146

Fabavirus, Gentian mosaic virus, new species, 192

Falk, K. R., 587

Fan, J. X., 433

Fang, H., 433

Farman, M. L., 640

Fassel, R., 963

Fauquet, C. M., 549

Fazari, A., 158

Feau, N., 608

Fermaud, M., 692

Fernández-Muñoz, R., 840

Fernando, W. G. D., 859

Ferrandino, F. J., 452

Fessehaie, A., 413

Field plots, image analysis, glare and shadow effect, S99

Fieselmann, D., 964

Finetti-Sialer, M. M., 262

Fiori, M., 1316

Flowers, microbial habitat, mutable, S128

Fofana, B., 114

Foissac, X., 617

Forbes, G. A., 1191, 1200, 1412

Forensic pathology, tan spot of bread wheat, 144

Förster, H., 751, 942

Foulkes, J., 62

Fountaine, J., 933

Fraaije, B. A., 933

Fraile, A., 827

Francis, D. M., 519

Fraxinus chinensis, Urapan disease, Colombia, S153

Freeman, M., 708

French, R., 1217

Friedt, W., 834

Friesen, T. L., 1144

Fry, W. E., 1191, 1200, 1412

FTA cards, Whatman, PCR amplification of nucleic acids, S35

Fuchs, M., 1151

Fucikovsky-Zak, L., 963, 964

Fujita, Y., 768

Fukuda, K., 737

Fukui, H., 784

Fumigation, plastic mulch bed, dichloropropene and methyl isothiocyanate, S16

Fungicides (general) (also see Fungicides, specific)

- premixing with famoxadone and cymoxanil, bacterial disease, S66

-resistance: apples, case study, S143; cereal pathogens, Europe, S143; cucurbit powdery mildew, S143; grape management, S143; industry approach, S143; QoI mechanisms and occurrences, S142; turf, QoI, S143

-SCALA brand SC, southern crops, S174

-small-scale spray heterogeneity, pathogen strains, 632

-turfgrass, dollar spot, S12

-wheat take-all, 62

Fungicides (specific) (also see Fungicides, general) 
- benomyl, resistance in field populations, S47

-benzothiadiazole, cotton leaf spot and dampingoff, 1030

-metalaxyl, irrigation effect, S21

-sampagine, natural-based, analogs, S2

-strobilurin, Septoria leaf blotch on wheat, resistance, 933

-validamycin A, tomato Fusarium wilt, validoxylamine A comparison, 1209

Fusarium spp.: asparagus crown and root rot, outbreak in Quebec, factors, 867; on cassava, complex in Africa, S125; on corn stubble, Connecticut, S27; on mango, malformation, $\mathrm{S} 125$; on potato, assay in stocks and soil, 1462 on potato, isolate variation, $\mathrm{S} 15$; on sorghum and millet, isolate comparison, 275; on sugar beet, field diversity, S40; on sweet pepper, fruit rot, molecular identification, 965

-F. circinatum, on pine: pitch canker, S124; temperature effect, S46

$-F$. foetens, on begonia, wilt, S169

-F. graminearum: hybrids, naturally occurring, S58; life cycle using genomics, S124; pathogenicity factors, S124; pathogenicity genes, targeted replacement, S163; on wheat, head blight, incidence in Ohio, 1049; on wheat, kernel infection, S167; in wheat, residue inoculum, green manure effect, S82; on wheat, residue management and resistance, S92; on wheat, scab, deoxynivalenol accumulation in grain, 1225; on wheat, virulence genes, 744; on wheat and rice, mycotoxins, 1397

-F. moniliforme, on sorghum, resistance and lignin, S32

-F. oxysporum: on Arabidopsis thaliana, molecular cytology of interaction, S53; on banana, cell wall degrading gene, 965; biocontrol agent with seven fungicides, $\mathrm{S} 31$; on chickpea, diversity after monoculture, S49; on cotton, strain diversity, Ivory Coast, 1391; on cyclamen, bioantagonists and fungicides, S168; host range, narrow or broad, S126; on melon, acibenzolar$s$-methyl, S119; on oil palm, review, S125; on Striga, "Achilles heel," S126; on tomato, biocontrol efficiency of nonpathogen, 1072; on tomato, control with validamycin A, validoxylamine A, 1209; on tomato, races and haplotypes, Taiwan, S95; on tomato, saline irrigation, 1438 on tomato, virulence and polymorphisms, S103

-F. solani: on bean, resistance evaluation, $\mathrm{S} 10$; coir effect, greenhouse, S46; macroarray for molecular detection, S98; on soybean, biocontrol test, S114; on soybean, long-term storage effect, S60

-F. verticillioides: on corn, fumonisin phytotoxicity mechanism, S118; on corn, phytoanticipins, $\mathrm{ABC}$ transporter, S79; on cotton, flower thrip association, S64; fumonisin biosynthesis, novel genes, S20; Fusarium spp. affected by, S92; GBP1 binding protein, S92 kinase gene, characterization, S112; on maize, starch influences fumonisin, S11

Fusicoccum sp., on pistachio, factors in California, 926

Gabriel, D. W., 918

Gadoury, D. M., 1445

Gaeumannomyces graminis

-on St. Augustinegrass, management in Georgia, S66

-on wheat: Brassica mulch effect, S78; epidemiology and chemical control, 62

Gáll, J. M., 1001

Gamliel, A., 1438

Gamliel-Atinsky, E., 1279

Garbelotto, M. M., 759

Garcia, V., 965

García-Andrés, S., 819, 1089

García-Arenal, F., 827
Garnsey, S. M., 909

Garzón, C. D., 1489

Gastrodia elata, lectin gene from, transgenic root disease, S22

Gaudio, L., 206

Gautheron, N., 1391

Gebre Selassie, K., 227

Geiser, D. M., 1489

Geminiviruses, weed infection, Jamaica, S20, S100

Gene collections, sampling strategies, S166

Gene silencing

-RNA, mechanism, S123; suppression by Plum pox virus, He-Pro, 894

—virus-induced, history, S132

Genome

-fungal and plant, DNA fingerprinting, S160

-fungi, structure related to gene expression, S56

- methylation filtration, gene discovery, S109

Genomics, Usilago maydis, deletion construction method, S35

Gent, G. H., 918

Gentian mosaic virus, Fabavirus sp., new, 192

Gentit, P., 617

Geraats, B. P. J., 808

Geranium

— bacterial wilt, resistant cultivars, S76

-black leg, microbial inoculants, S172

- Southern wilt, race 3 biovar 2 behavior, 136

Gessler, C., 672

Gevers, T., 965

Gibberella spp.

-G. circinata: spore germination and growth inhibition, pine resin, S32; vegetative compatibility, changes, S83

-G. fujikuroi: fumonisin production, phylogenetics, S173; on rice, seed sources, California, S4

-G. zeae: aerobiology and population structure, S127; genetic map, sequence-tagged sites, $\mathrm{S} 162$; on wheat, flowers colonized by, S129; on wheat, spore deposition patterns, 472; on wheat, wild and mutant strains, cover photo, July; on wheat, wind and rain splash, canopies, S81

Gilligan, C. A., 62, 632

Gilmore, B., 292

Ginseng (see also Panax quinquefolius)

- fungal pathogens, in soil, S88

Global movement

-APHIS-PPQ system, session, USA, S142

—biosecurity, NPDN, S142

- Canada regulations, perspective, $\mathrm{S} 142$

—industry perspective, S142

-regulations, European perspective, S142

Global warming, coralline lethal algal disease, S120

Globodera rostochiensis, on potato, monoxenic root culture, S109

Glomerella cingulata, on camellia, fungicides and inoculation, S66

Goates, B., 961

Gobbin, D., 672

Goffinet, M. C., 362

Gognalons, P., 227

Goldbach, R., 852

Goldberg, N., 1217

Gollop, N., 1341

Gómez-Guillamón, M. L., 840

Gonthier, P., 759

González-Jara, P., 894

Gorovits, R., 397

Goss, E., 961

Goswami, R. S., 1397

Gottschalk, K., 960

Gout, L., 1061

Graham, J. H., 1333

Grape

—bacterial community, rhizosphere and soil, S80
-Botrytis bunch rot: factors, S169; saprotrophy and virulence, 692

- crown gall, auxin and wood position effects, 362

-disease susceptibility, cultivars, $\mathrm{S} 8$

-downy mildew: berry and rachis infection, 1445; carbon partitioning, S58; host specialization, S58; photosynthesis effect, S170; quantification using PCR, 672

-fungicide resistance management, S173

-myclobutanil, disease control, S78

- ontogenic resistance, climate-based modeling, S33

-Petri disease, green detection, S172

-Phomopsis cane and leaf spot, management strategy, S128

-Phomopsis leaf and cane spot, spatial patterns in Ohio, S76

-Pierce's disease: plant/insect interface, S9; resistance, stem and leaf populations, 44; resistance, symptom indices, 36; symptom anatomy, S99

—postharvest gray mold: biofumigation, 963; chitosan for control, S90

- postharvest pathogens, sulfur dioxide, S79

- powdery mildew: control in California, S57; eradicant fungicides, S7; field resistance, S71

—-stolbur phytoplasma, detection, Spain, S153

Grapevine fanleaf virus

-retention in absence of host, 1151

-on Xiphinema index, detection through DNA probes, 262

Greco, N., 339

Greenhouse, mobile containment laboratory, development, S80

Greenhouse perennials, tumors and galls, bacterial cause, $\mathrm{S} 70$

Griffin, J. L., 220

Grodzinski, B., 354

Groenewald, J. Z., 951

Groenewald, M., 951

Groenewald, S., 965

Groves, R., 708

Grünwald, N. J., 1412

Gudino-Oceguera, J., 963

Guérin, G., 405

Guetsky, R., 1341

Guignardia citricarpa, on citrus, re-identified in

New Zealand, S28

Guo, B. Z., 381, 506

Gutierrez, L. J., 715

Hadar, I., 1341

Hagiwara, K., 192

Hahn, M., 153

Hahn, V., 834

Halbrendt, J. M., 1116

Hamel, C., 867

Hamelin, R. C., 608, 793, 960

Hamon, P., 600

Hansen, M. E., 1021

Hanson, K. A., 198

Hao, G., 961

Harel, A., 397

Harrington, T. C., 316

Hasenstein, K. H., 101

Hassani-Mehraban, A., 852

Hataya, T., 128

Hay, F., 648, 964

Hayden, H. L., 489

Health, hazards, laboratory, mycotoxins, session, S146

Heijne, B., 1001

Hemileia vastatrix, on coffee, biocontrol, S63

Herbicide

- glyphosate, on wheat, rust resistance, 960

- protoporphyrinogen oxidase inhibitor, sugarcane root rot, 220

Herrera, C., 965 
Heterodera spp., spore deposition, seasonal patterns in Alps, 759

- H. glycines: on soybean, virulence genes, genetics, 186; suppressiveness in soil, factors, S 157

-H. schachtii: on sugar beet, survival factors, 339; suppression by Dactylella oviparasitica, management strategy, S77

Hiddink, G. A., 1325

Hijmans, R. J., 1191, 1200, 1412

Hilf, M. E., 909

Himmel, P., 961

Hoekstra, M., 962

Holb, I. J., 1001

Holbrook, C. C., 381, 506

Honda, Y., 192

Host-pathogen relations, wild populations, gene deployment, S99

Hou, Z., 744

Howard, R., 965

Hoy, J. W., 220

Hsu, H.-T., 1482

Hückelhoven, R., 528

Hughes, G. R., 172

Hulbert, S., 961

Hyakumachi, M., 784

Hydrilla verticillata, indigenous pathogen, management, S120

Ibarra-Medina, V., 964

Ibeagha, A. E., 528

Idris, A. M., 549, 962, 1217

Impatiens necrotic spot virus

-on pepper, host range, S73

- phylogenetics, protein genes, S1

Imperata cylindrica, leaf blight, etiology, S103

Inoue, K., 1137

Integrated pest management (see also Management)

- grape soilborne pests, methyl bromide, S139

—integrated measures, global trade, S131

- potato diseases, green manure and crop sequence, indigenous Streptomyces, 178

IR-4 biopesticide program, grants and registration, S13

IR-4 project, fungicide registration, update, $\mathrm{S} 103$ Iris yellow spot virus, detection by RT-PCR, 963

Irrigation, saline, tomato crown and root rot, 1438

Ishida, M., 962

Ishikawa, R., 1209

Ishimaru, C. A., 918

Jabaji-Hare, S., 1030

Jackson, R. W., 1316

Janse, J. D., 1316

Janssen, D., 1089

Japaji-Hare, S., 345

Jeannotte, R., 867

Jeger, M. J., 1001

Jiménez Díaz, R. M., 368

Jochum, C. C., 701

Johnson, K.B., 1072

Johnstone, M., 354

Joshi, R., 715

Juárez, H. S., 1200

Juzwik, J., 960

Kabbage, M., 961

Kader, K. A., 1472

Kaewnum, S., 962

Kakutani, K., 1137

Kaminski, J. E., 1356

Kandel, Y. R., 248

Kang, S., 1248

Katan, J., 1438

Kemen, E., 153

Kennelly, M. M., 1445

Kerkvliet, J., 962

Kerns, J., 962

Kessel, G. J. T., 328, 439
Khan, J., 962

Kharbanda, P., 965

Kilaru, A., 101

Killiny, N., 541

Kim, K. S., 1122

Kim, S., 1248

Kinkel, L. L., 178

Kirkpatrick, B. C., 581

Kishore, G. K., 1157

Kistler, H. C., 744, 1397

Kitajima, E., 963

Klein, K. K., 1144, 1391

Knierim, D., 659

Kobayashi, A., 192

Kobayashi, D. Y., 701

Kobayashi, Y. O., 192

Kobiler, I., 1341

Koenraadt, H., 962

Kogel, K.-H., 528

Köhl, J., 439

Kolmer, A. J., 773

Kolmer, J., 960

Kormelink, R., 852

Koutsoudis, M., 965

Koyanagi, S., 640

Kraft, J. M., 1287

Krall, E., 1308

Krivanek, A. F., 36, 44

Krueger, W. H., 1132

Kubisiak, T. L., 376

Kubota, M., 784

Kurowski, C., 961

Kusaba, M., 640

Kusakari, S., 1137

Labbé, C., 114

Labonne, G., 1453

Labyrinthula terrestris, temperature and salinity effect, S83

LaFlamme, G., S173

Lamari, L., 144

Lamprecht, S. C., 275

Larrea tridentata

-biocontrol for pepper, soil solarization comparison, S150

-extracts, antifungal, S150

Larsen, R. C., 1037

Latchman, B., 1301

Latham, R., 964

Lazarovits, G., 28

Lebas, B., 963

Lecours, N., 793

Lee, H.-K., 1112

Lee, H.-Y., 1209

Lee, R. D., 381

Lee, Y.-H., 1248

Lees, A. K., 1462

Lehman, J. S., 198

Leifsonia xyli, on sugarcane, detection by realtime PCR, S36

Leite, B., 962, 963

Leonard, K. J., 53

Leptographium spp., on loblolly pine, vectors in southeastern USA, S27

-L. wageneri, on ponderosa pine, prescribed burning relation, $\mathrm{S} 78$

Leptosphaeria maculans, race structure, worldwide collection, 1061

Lerceteau-Köhler, E., 405

Leslie, J. F., 275

Letter to the Editor, rainfall, radar-estimated, disease risk forecast, 25

Lettuce, downy and powdery mildew, chemical management, S67

Lewis Ivey, M. L., 519

Li, H., 1061

Li, Z., 902

Liang, X. Q., 506

Liberti, D., 420
Lievens, B., 1374

Lin, Y.-H., 1482

Lin, Y.-Z., 1482

Lindenthal, M., 233

Lindera melissifolia, Botryosphaeria stem canker and dieback, black twig for relation, Mississippi, S112

Lipps, P. E., 1049, 1225

Liu, F.-L., 1482

Liu, J.-J., 284

Liu, Q., 572

Liu, X. Z., 566

Lolium perenne, gray leaf spot, silicon effect, S73, S172, 966

Long, R., 960

Longidorus spp., Xiphinema comparison, species diagnosis, $\mathrm{S} 141$

Loreti, S., 1316

Lorito, M., 206

Louws, F. J., 918, 1098

Lovell, D. J., 933

Lu, B. S., 566

Lucas, J. A., 933

Luo, C.-X., 640

Luo, M., 381

Luo, P. G., 1266

Luo, Y., 1132

Lutton, E., 715

Lynch, R. E., 381, 506

Lyon, G. D., 1368

Lysobacter enzymogenes

-biocontrol agent, ceramide synthesis, S116

-Bipolaris leaf spot of tall fescue and Pythium damping-off of sugar beets controlled by, 701

MacDonald, W., 960

Madani, M., 1308

Madden, L. V., 874, 1049, 1225

Magarey, P. A., 1445

Magarey, R. D., 92

Magnaporthe spp.

-M. grisea: race shift, major $\mathrm{R}$ gene, Arkansas, $\mathrm{S} 175$; on rice, avirulence gene, Pik locus, 768; on rice, canopy moisture effect, 433; on rice, circadian syntenic blocks, S57; on rice, cultivars in Brazil, S84; on rice, cultivar symptoms, cover photo, November; on rice, defense mechanisms, 1248; on rice, genetic analysis, signal transduction, $\mathrm{S} 48$; on rice and non-rice hosts, avirulence gene AVR-Pita, S13; on ryegrass, azoxystrobin resistance, sensitivity, S63; on ryegrass, azoxystrobin sensitivity, S170; on St. Augustinegrass and tall fescue, genetics, 463

$-M$. oryzae, on rice, avirulence genes, cultivar specificity, 640

Magnolia virginiana, dye penetration through lenticels, 965

Mahaffee, W. F., 306

Maiss, E., 659

Maize (see also Corn)

- downy mildew, screening lines, S151

-Fusarium spp., populations in Ghana, S58

- gray leaf spot, modeling, regression and artificial neural network, 388

-lipoxygenase genes, defense-related, S75

-nematode interaction, lipoxygenase role, S33

-Penicillium mycotoxins, frequency, S64

-silage, mycotoxins, S171

- southern leaf blight, gray leaf spot, resistance, S6

-sphingolipid role, germination, $\mathrm{S} 83$

Maize chlorotic dwarf virus, coat protein 1, sphingosine kinase-like protein, S87

Maize fino virus, ecology and evolution, S40

Maize stripe virus, Maize mosaic virus comparison, resistant inbreds, vector relation, 600

Maldonado, J. A., 819 
Malpica, J. M., 827

Management (see also Integrated Pest Management)

- $\operatorname{Aran}^{\mathrm{TM}}$ process, 963

-damage and price functions, S131

-ecological patterns and micromanagement, S130

-epidemiological models, S131

— global, strong borders case, S131

- loss assessment, grape growers, S131

—pathogen detection arrays, 1374

-risk prediction, specialized models, S131

Manceau, C., 1081

Manganese, oxidation, pathogen effect, S166

Manisterski, J., 53

Manter, D. K., 1256

Manuscript preparation, authors guide, 7

Maoka, T., 128

Maple, powdery mildew, analysis, 964

Marais, A., 420, 617

Marasas, W. F. O., 275

Marchesi, U., 1316

Marchoux, G., 227

Marek, S., 1112

Marques, L., 963

Martin, R. R., 1043

Martinez, F., 692

Martínez-García, B., 894

Martínez-Ramírez, J., 963, 964

Maruthi, M. N., 1472

Mason, G., 800

Masunaka, A., 241

Matsuda, Y., 1137

Mavrodieva, V. A., 909

McCallum, B. D., 144

McGee, R. J., 1287

McKenry, M. V., 581

McNally, D. J., 114

McPherson, M., 963

McSpadden Gardener, B. B., 715

Medicago spp., Phymatotrichum root rot, growth chamber assay, 1112

-M. trucatula: anthracnose and powdery mildew, interaction analysis, S162;

rust, resistance mechanisms, 153

Meira spp., antagonism to plant pathogens, S81

Meloidogyne spp.: on Capicum annuum, root inoculation, cover photo, February; on Capsicum аппиит, resistance, histology and phenolics, 158; on chickpea, feeding site differences, 368

-M. artiellia, on chickpea roots, cover photo, April

-M. incognita: abamectin sensitivity, S28; on cantaloupe, factors, S70; on cotton, soil texture effect, S175; on legumes, suppressiveness screening, S109; parasitism genes, functiona analysis, S45; quantification, imaging system, $\mathrm{S} 14$; on rye, chemical toxicity, S160; on Secale cereale, hydroxamic acids, 1116; on tomato, biocontrol affected by good source, S53

Melon (see also Cucumis melo and Watermelon)

- foliar diseases, chlorothalonil, S52

- powdery mildew, quantitative trait loci mapping, 556

Melon chlorotic leaf curl virus

-infectious clones, S150

-intermolecular reassortment, S70

Méndez-Morán, L., 480

Mendgen, K., 153

Mentha spp.

-Closteroviridae, novel member, 1043

-disease symptoms, cover photo, September

Mercier, J., 963

Merino, F., 1423

Merremia mosaic virus, on weeds, Puerto Rico, S7

Metrosideros sp., foliar rust, Hawaii, 965

Mew, T. W., 433

Meyer, S. L. F., 1116
Michailides, T. J., 926, 1132

Microarray, gene identification, defense, S122

Microorganisms, collections, endangered, S4

Miklas, P. N., 499, 1037

Mikoshiba, Y., 192

Mila, A. L., 926

Milgroom, M. G., 300

Miller, S. A., 519

Minot, J.-C., 1151

Mite, mycophagous, fumigation control method, $\mathrm{S} 112$

Miwa, C., 1072

Mlikota Gabler, F., 963

Mmbaga, M., 964

Model (see also Disease forecasting)

- analytic hierarchy process, exotic plant pests, 964

—apple scab epidemiology, nonlinear mixed effect, 1001

- assessment dates, permutation tests on lattice, 1453

- foliar fungal pathogens, generic infection, 92

- host-parasite coevolution, system stability, 728

-LATEBLIGHT, qualifications over environmental ranges, 1412

-maize gray leaf spot, neural network, 388

— potato LATEBLIGHT, 1191

- potato late blight, LATEBLIGHT validation, 1200

- SADIE indices, spatial patterns of organisms, 874

— soybean rust, fuzzy logic system, 1122

- Swiss needle cast disease, Oregon, 1256

-Wheat stripe rust, epidemic velocity, 992

Moens, M., 1308

Monci, F., 819

Monilia fructigena, on small fruits, Kazakhstan, 960

Monilinia spp.

-M. fructicola, on stone fruits: benzimidazole resistance, detection in California, S63; latent infection, California, 1132

-M. vaccinii-corymbosi, on blueberry: biocontrol agents, S103; flower infection, S129; fungicides, S102; yield effect, bud phenology, 1174

Montesinos, E., 1430

Moorman, G. W., 1489

Morena, V., 1271

Morgan, D. P., 926, 1132

Morilla, G., 1089

Moriones, E., 819, 840, 1089

Moriura, N., 1137

Motoyama, T., 1209

Motteram, J., 933

Moury, B., 227

Mrema, F., 964

Muehlbauer, F. J., 1287

Mundt, C. C., 433, 972, 983, 992, 1363

Munkvold, G. P., 388

Muscodor albus

-biofumigant for root disease, vegetable production, S42

-on rye, postharvest fumigation, $\mathrm{S} 48$

Mycoherbicides, orphan, future, S125

Mycorrhizae, arbuscular, beta-tubulin gene, S157

Mycospharerella spp.

-M. graminicola: on cereals, resistance in Northern Ireland, S67; factors and status in UK, S30; field populations, fungicide resistance, 933; population variability, microsatellite markers, S35; on wheat, isolate-specific resistance genes, 664; on winter wheat, long-distance spring infection, 961

-M. musicola, on banana, Australian populations in genetics, 489

-M. populorum, on poplar, populations in North America, genetics, 608

Mycotoxin

-Alternaria alternata, ACT- and ACR-toxins, on citrus, 241

-deoxynivalenol, wheat scab, 1225

-Fusarium, preharvest forecasting, S123

-Fusarium graminearum on wheat and rice, accumulation, 1397

- solanapyrone, Alternaria solani and Ascochyta rabiei, biological activity, S134

-trichothecene, biosynthesis in Fusarium, genetics, S124

Myers, J. R., 292

Naito, T., 192

Nakano-Hylander, A., 867

Nakashita, H., 1209

Nanayakkara, U., 966

Narasimhan, B., 25

National Plant Diagnostic Network, status after two years, S163

Nault, B. A., 1405

Neate, S. M., 1030

Necrotrophy, hemibiotrophs, relations, S136

Nelson, C. D, 376

Nelson, R. J., 1191

Nematodes

—isozyme phenotypes, challenges, S141

- molecular diagnostics, S141

-quarantine, molecular tools, seession, S141

- Tylenchid, molecular identification, S41

Neotyphodium coenophialum, on tall fescue, endophyte extracts, pathogenicity, S5

Nervo, G., 800

Newcombe, G., 779

Newton, A. C., 1368

Nicole, M.-C., 793

Nicolotti, G., 759

Nishimura, H., 1137

Nitzni, Y., 1279

Nnodu, E., 964

Noguchi, M. T., 768

Nonomura, T., 1137

Nottéghem, J.-L., 1081

Nucleotide Analysis Programs, population data analysis, $\mathrm{S} 85$

Nutter, F. W., Jr., 648

Oak

— sudden death: Maryland, S158; pathogen transmission, California, 587; tanoak susceptibility, S41

-wilt: beetle vector, Minnesota, S161; propiconazole, detection, S10; propiconazole, preventative and therapeutic, S166

Oat, crown rust, virulence associations, 53

Ochoa Corona, F., 963

Oelke, L. M., 773

Oerke, E.-C., 233

Ogata, D., 965

Ohtani, K., 241

Oidium neolycopersici, on tomato, gene detection, PCR, 1137

Ojiambo, P. S., 108

Oldrup, E., 964

Olive, Verticillium dahliae, Jordan, S39

Olson, M., 963

Omura, T., 192

O’Neill, N. R., 1356

Onion

-Botrytis neck rot, pink root, fungicides, S176

—nematodes, Mexico, S151

-Xanthomonas leaf blight, pathovar relatedness, 918

Oomycetes, transcriptional regulatory sequences, evaluation, S32

Ophiosphaerella

-O. agrostis: ascospore release, environment effect, 1356, S170; on bentgrass, overwintering, S169

-O. herpotricha, on bermudagrass, on stolons and roots, $\mathrm{S} 107$ 
-O. korrae, on bermudagrass, fungicide programs, S104

Ophiostoma novo-ulmi, pathogenicity genes, S84

Opperman, C. H., 186

Orange, Septoria spot, temperature effect, S70

Ornamentals, Phytophthora root rot, fungicides for, $\mathrm{S} 174$

Ostrow, K. M., 1217

Oudemans, P.V., 1237

Oxytropis sericea, swainsonine production, environment parameters, 964

Paenibacillus polymyxa, Phytophthora capsici inhibited by, in chili pepper, S54

Pahalawatta, V., 427, 884

Palumbo, J. D., 701

Panax quinquefolius, (see also Ginseng)

—root rot, factors, 1381

Pande, S., 1157

Panfili, G., 1271

Pantoea stewartii, on maize, biological function, 965

Papaya

- phytoplasma, Taiwan, S7

-yellow crinkle, survival and pattern analysis in Australia, S128

Papaya leaf distortion mosaic virus, nucleotide sequence, biotype variability, 128

Papaya ringspot virus, on cucurbits, engineered strains, 533

Parnell, S., 632

Pastoor, R., 808

Pataky, J. K., 85

Patocchi, A., 672

Patterson, H. A., 587

Paul, P. A., 388, 1049, 1225

Paveley, N., 62

Pea

-Fusarium solani, nonhost resistance, inhibitors and effectors, S40

—nitric oxide synthase, plant interaction, S113

-nonhost resistance, inhibitor array, S39

-root rot: North Dakota survey, S36; resistance loci, USA and France, 1287

Peach

-bacterial canker, syringomycin production, nitrogen effect, 581

-bacterial spot, symptom development, S89

_rust, initial infection, 942

-rusty spot, management program in orchards, S62

—scab, fungicide programs, S93

Peanut

-ABSOLUTE 500 SC for control, S175

-Aspergillus flavus, glucanase and conglutin-like protein, 506

-bahiagrass rotation, Florida, S104

- Cylindrocladium black rot, metam sodium control, S174

- disease resistance, lines, S39

-late leaf spot, biocontrol with bacteria, 1157

-leaf spot, transcripts in resistance responses, 38

- leaf spot and tomato spotted wilt relation, multiple locations, S175

- pod rot, microbial and organic amendments, S92

-Sclerotinia blight, Georgia, S176; previous crops, S69; weather data, prediction, S176

Pear

-blue mold, etiology in California, S30

-fire blight, disease-dose and time relations, 1430

- genetic transformation and regeneration, S160

-Phacidiopycnis rot, chemical and biocontrol, S113

- stem-end decay, biocontrol in storage, S48

Peever, T. L., 241, 512

Pegard, A., 158
Peirson, D., 965

Pelloix, A., 227

Penicillium spp.

$-P$. digitatum, on citrus, postharvest fungicide resistance, $\mathrm{S} 51$

- P. expansum: on apple, fungicide resistances, S59; patulin, apple accumulation, biocontrol, 1271; phenylpyrrole fungicide fludioxonil sensitivity, S77

Penman, L. N., 1174

Pennisetum glaucum, Fusarium spp., sorghum isolate comparison, 275

Pepino mosaic virus

-detection by PCR, S50

- strain typing, S76

-on tomato: PCR detection, S61; phylogenetic analysis, Canada, S31

Pepper golden mosaic virus, complex, variation, 1217

Pepper veinal mottle virus, molecular and pathotype diversity, serology, 227

Perchepied, L., 556

Perlman, N., 1341

Peronospora spp

$-P$. antirrhini, on snapdragon, fungicides, S154

$-P$. statices, on limonium, fungicides and adjuvants, $\mathrm{S} 110$

Persea borbonia, dye penetration of lenticel, 965

Pertot, I., 672

Pest management (see Integrated Pest Management)

Pesticides, systemic toxicants, application through lenticels, 965

Peters, D., 852

Pethybridge, S. J., 648, 964

Petunia

- foliar and root fungal pathogens, susceptibility, S77

-late blight, greenhouse management, S8

- tobamovirus, Mississippi, S92

Peyrard, N., 1453

Pfarming

-future, S130

-implications, S130

—regulatory perspective, S130

Phaeoacremonium viticola, on grape and ash, $\mathrm{S} 28$

Phaeocryptopus gaeumannii, on Douglas-fir, needle cast model, Oregon, 1256

Phaeoisariopsis spp.

-P. griseola, on bean: epidemic modeling, S93, infection, S64

$-P$. personata, on peanut, biocontrol with bacteria, 1157

Phaeosphaeria spp., beta-tubulin gene, S159

$-P$. nodorum, on wheat, population structure, New York, 300

Phakopsora pachyrhizi, on soybean:

-alternative hosts, Mexico and Central America, S82

-ELISA, S85

- proteins in germination, S63

-system map, Brazil, S16

Phaseolus spp.

-P. coccineus, white mold, oxalates and susceptibility, 292

-P. vulgaris: bacterial blight, resistance, S26, bean leaf crumple, begomoviruses, single gene, 819; leaf spots, polyphasic characterization, S97; pod rot, resistance and culture factors, S102; Pythium root rot, Eastern Africa, S15; resistance, pyramiding, S122; Rhizoctonia solani, nonpathogenic isolate effect, gene transcripts, 345; rust, simulation model, Kenya, S105; white mold, oxalates and susceptibility, 292

Phialophora gregata, on soybean, PCR interaction, S64

Phoma spp.

-P. exigua, on Acroptilon repens, vectors in greenhouse, S156

-P. ligulicola: genetic variability, Australia, 964; on pyrethrum, epidemic description, 648

-P. macrostoma, worldwide collection, AFLP analysis, $\mathrm{S} 83$

Phomopsis longicola, on soybean, vegetative compatibility, Arkansas, S98

Phylolacca heterotepala, ribosome-inactivating protein, tobacco resistance to pathogens, 206

Phymatotrichopsis omnivora

—on alfalfa, electron microscopy, 1112

- culture media, 1112

-molecular phylogeny, S65

Physalospora vaccinii, on cranberry, decontaminant chemical model, S105

- P. cactorum: on ginseng, characterization, $\mathrm{S} 163$; on ginseng seed, mefenoxam resistance, $\mathrm{S} 42$; population variation, California, S9; on strawberry, strobilurin fungicide azoxystrobin, $\mathrm{S} 87$

Phytophthora spp.: AFLP analysis, North America and Europe, S62; on asparagus, Michigan, S92; on cacao, relation with witches'-broom, 1301; on cranberry, sporangia in oospores, cover photo, October; detection in soil, treatments, S119; in mountain streams, detection, S46; in nurseries, irrigation and fungicide effects, S100; nursery spores in parks in Virginia, survey, S44; on oak, ecosystems in Appalachian forests, S155; on oak, central and eastern USA, 960, S158; on petunia, root and crown rot, Virginia, S159; woody plants in Minnesota, S94

-P. capsici: on bean, cucumber and soybean, S162; on chili pepper, biocontrol, S99; on cucumber, resistance method, S34; on cucurbits, management, S4; mefenoxam sensitivity, Florida, S31; oospores, enumeration in soil, $\mathrm{S} 81$; on pepper, biosurfactants in management, $\mathrm{S} 75$; on pepper, genotype reaction, 1423; on pepper, fluorescent pseudomonads and chemical control, S79; on pepper, root-knot resistant relation, S115; survival in water, dissemination, S172; Verticillium dahliae co-infection, chili pepper, $\mathrm{S} 92$

- P. cinnamomi: on avocado, suppression in soil, S68; on cranberry, root and runner rot in New Jersey, 1237; ornamental nurseries, mefenoxam and propamocarb sensitivity, S45

- $P$. cryptogea, zoospores, temperature effect, $\mathrm{S} 107$

-P. erythroseptica, on potato, mefenoxamresistant isolates, $\mathrm{S} 84$

-P. fragariae, on strawberry, biocontrol, $\mathrm{S} 4$

$-P$. infestans: competitive selection, USA and Ireland, S167; post-infection and fungicides, S34; on potato, competition and aggressiveness effect, Michigan, S116; on potato, epidemic development, host diversity effect, mixture theory, 328; on potato, mitochondrial genome, S89; on potato, model, Andes, 1191; on potato, solar radiation effect in Mexico, S149; on potato, sporulation on tubers, S34; on potato and tomato, temperature and relative humidity, S77; race composition, Taiwan, S109; South American origin, gene genealogies, S89; survival on debris and hosts, Brazil, S71; on tomato, gene profiling, S88; on tomato, protein secretion during infection, S52

- P. ipomoeae, in Mexico, wild species, S149

- $P$. nicotianae, ornamental nurseries, propamocarb resistance, $\mathrm{S} 159$

- $P$. parasitica, races 0 and 1, molecular characterization, $\mathrm{S} 101$

- P. phaseoli, on lima bean, fungicide trials, S155

- $P$. ramorum: in California streams, monitoring, S72; on camellia, detection with PCR and ELISA, S15; on camellia, resistance, S157; chlamydospores, survivability, S20; on lilac, 
S160; mixed-evergreen forest, transmission in California, 587; in nurseries, New York survey, S98; on oak, PCR detection, sensitivity, S106; in ornamental nurseries, Georgia, S111; on ornamentals, container-grown, soilless mixes, $\mathrm{S} 48$; on ornamentals, USA nurseries, S90; in potting mix soil, survival, steam treatment, $S 61$; on rhododendron, new lineage in Californa, S9; on rhododendron, temperature and moisture effect, S104; on rhododendron and lilac, chemical control, S61; surfactant effect, S115; survival in soil, seasonal, S29; on Viburnum, resistance, S37; on weeds, root and shoot infection, $\mathrm{S} 96$

$-P$. sojae: $L P V$ genes, repetitive sequence, $\mathrm{S} 55$; on soybean, metalaxyl sensitivity in North Dakota, S74; on soybean, pathotypes in Nebraska, S93; on soybean, resistance screening in germplasm collection, $\mathrm{S} 163 ;$ P. ramorum comparison, microsatellite, S37

Phytoplasma

- aster yellows, small grains in Minnesota, S43

- clover phyllody: onion yellows, comparative analysis, S159; clover phyllody, prokaryotic protein, S157

- fruit yellows, stone fruits, Spain, S153

-genomes: gene cluster, S156; tropomyosin-like domain, S50

- phylogenetic relations, S169

—witches'-broom association, China, S117

Phytotoxin

- apoptotic core of pathegenesis, S133

— fungal, session, S133

—patulin, yeast for biocontrol, 1271

- perspectives and promises, S134

Pilet-Nayel, M. L., 1287

Pillinger, C., 62

Pine

-blister rust, hybrids, S39

-decline, monitoring in southern USA, S42

-fusiform rust, gall-free seedlings, S176

-loblolly: decline risk mapping system, S69; fusiform rust, resistance gene $\mathrm{Fr} 1,376$

-Scleroderris canker, snow factor, $S 173$

— shortleaf, fusiform rust, mortality, S108

Pineapple

- heart rot, bacterial characterization, Hawaii, S107

- systemic acquired resistance, time course, S19

Pinus spp.

-P. banksiana, Scleroderris canker, American race, $\mathrm{S} 170$

$-P$. monticola, rust, chitinase and canker growth, stress, 284

-P. resinosa, root pathogens, biocontrol, S166

-P. strobus, blister rust, molecular epidemiology, 793

-P. thunbergii, wilt, pinewood nematode, xylem cavitation, 737

Pistachio, panicle and shoot blight, factors in California, 926

Pitkin, Y., 1462

Pitrat, M., 556

Plasmopara viticola, on grape:

- berry and rachis infection, 1445

— forecasting and management, S127

—quantification, PCR, 672

- ontogenic resistance to downy mildew, cover photo, December

Plectosporium tabacinum, on cucurbits, New England isolates, S98

Plum pox potyvirus

-host shifting and transmission mode, S157

—on peach, strain interaction, $\mathrm{S} 22$

-population diversity in Pennsylvania, S94

Poa trivialis, Pythium irregulare, Florida, S100

Podile, A. R., 1157

Podosphaera spp.

-P. clandestina: on cherry, detection using PCR, S16, S37
-P. macularis, on hop, detection and quantification, $\mathrm{S} 81$

-P. xanthii: on cucumber, induced resistance, flavonoid pathway disruption, 114; on cucurbit, strobilurin fungicides, S12; on melon, fungicides, California, S105

Poehling, H.-M., 659

Polashock, J. J., 1237

Populus spp., nonhost resistance, parasite-specific genes, 779

$-P$. deltoides, leaf spot and canker, population structure in North America, 608

Posos-Ponce, P., 963, 964

Postharvest disease

—biofumigation, Muscodor albus, S141

- fungicides, fresh fruit, S140

-management, field to packinghouse, S140

-management strategy: fungicides and resistance, S140; host resistance, session, S140

-nonchemical control, fruits and vegetables, S141

Postharvest pathology

- chlorine dioxide, sinks, S7

—citrus black rot, phylogenetically distinct lineages, 512

- pome fruit, hexanal vapor, S96

-microbial biofilms, sanitation protocols, S65

Postma, J., 808

Postman, J. D., 1043

Potato (see also Solanum tuberosum)

-bacterial wilt: biocontrol with pseudomonads, S85; resistance sources in wild species, S85

-breeding lines, Potato virus Y, S164

-Colletotrichum coccodes, stem colonization, S76

—cultural and biocontrols, S139

- cyst nematode, parasitism genes, S103

-Fusarium dry rot: assay in stocks and soil, 1462; diploid hybrid, resistance, S15, S168; seed transmission and fungicides, S110

- Irish famine compared to sudden oak death, social impact, S129

-late blight: epidemics and yield, models, S98; LATEBLIGHT model validation, 1200; $R B$ orthologous genes, S62; simulation in Andes, model, 1191

-LATEBLIGHT, simulation model, 1412

-Rhizoctonia, fungicides, management, S111

— scab, resistance, S163

- scab and Verticillium wilt, green manure and crop sequence effect, 178

- soft rot, strain diversity in Russia, S160

- soil organisms, cropping systems and amendments, S56

- tuber necrosis, virus diagnosis, S114

- tuber pathogens, detection in storage, S51

- viruses, detection assays, S73

Potato leafroll virus, coat protein monomers, aphid transmission, S82

Potato spindle tuber viroid, RT-PCR detection, template preparation, S97

Potato virus $X$

—nuclear targeting assay, S158

_Plum pox virus vector, synergism, 894

Potato virus $Y$

-resistance-breaking, evolutionary process, $\mathrm{S} 2$

-on tuber, cultivar, S6

Potato yellow mosaic virus, genome sequence, Puerto Rico, S46

Potebniamyces pyri, conidial germination, factors, 572

Powell, J. A., 328, 439

Prathuangwong, S., 962

Pratt, R. G., 1183

Pratylenchus penetrans, on apple, management, S10

Premachandra, W.T. S. D., 659

Press, M. C., 1294

Priyatmojo, A., 784
Prunus spp., black knot, genetic diversity and structure, 859

- P. domestica, brown rot, latent infection, 1132

-P. virginiana, $\mathrm{X}$-disease, monitoring, $\mathrm{S} 108$

Prusky, D., 1341

Pseudomonads, stress tolerance, phase dependent on/off switch, S30

Pseudomonas spp.: biocontrol potential for corn and soybean fields, rhizospheres, 715; in rhizosphere, farming and soil factors, S38; on spruce nursery and natural forest, phenazine and phloroglucinol-producing, 960

-P. fluorescens: on apple and pear, iron chelate for control, S100; siderophore, biosynthesis genes, S5; on wheat, rhizosphere population, $\mathrm{S} 11$; on wheat, rhizosphere relation, $\mathrm{S} 4$

-P. putida: on Arabidopsis thaliana, rhizosphere, gene expression, S110; on eucalypt, diacetylphloroglucinol suppression, S5

-P. syringae: on cherry, genetic analysis in Michigan, S88; on coriander, development, $\mathrm{S} 11$; on coriander, splash dispersal, S12; on Corylus avellana, twig dieback, 1316; host ranges, 16-kb genomic island, $\mathrm{S} 87$; on peach, syringomycin production, nitrogen effect, 581; phytotoxins, regulatory protein, S109; plasmid family, molecular evolution, S117; tagetitoxin production, genes, S156; on tomato, choline and betaine uptake, $\mathrm{S} 18$; on tomato, protein tyrosine phosphatase effector, S48; on tomato, screening with seedling assay, S40; type III chaperones, homologs, S103; type III effectors, identification, S38; type III effectors, secretion signals, S34; type III secreted effector protein, autoribosylates, S32

-P. viridiflava, on Arabidiopsis thaliana: jasmonic acid defense pathway, S47; variation patterns, 961

Pseudoperonospora cubensis

- on cucumber, transpiration and thermography, 233

-on melon, quantitative trait loci mapping, 556

Pseudotsuga menziesii, Swiss needle cast, climate-based model, Oregon, 1256

Pseudozyma flocculosa, biocontrol agent, genetic analysis, S171

Puccinia spp., detection and identification, molecular methods, S166

-P. coronata, on oat: quantified by $\mathrm{PCR}, \mathrm{S} 47$; virulence associations, 53

- $P$. graminis: detection in rain, S6; EST analysis, cDNA libraries, S118; on wheat, African isolates, resistance, $\mathrm{S} 49$

-P. hemerocallidis: on daylily, nickel effect, S88; on daylily, resistance, S61; urediniospore germination, media and $\mathrm{pH}$ effect, $\mathrm{S} 60$

-P. hordei, molecular diversity, S101

$-P$. horiana, on chrysanthemum, regulation in Pennsylvania, S54

-P. psidii, on Melaleuca quinquenervia, in Florida, S87

-P striiformis: on barley, recessive gene mapping, S115; on barley, unfavorable host, molecular mapping, 884; on barley and wheat, resistance genes, molecular mapping, 427; on Canada thistle, biocontrol, S24, S156, S168; on wheat, disease gradients in field, 983; on wheat, epidemic velocity, 972, 992, 1363; on wheat, resistance gene, diagnostic markers, 1266; on wheat, USA epidemic in 2004, S19

-P. triticina: on durum wheat, worldwide collection diversity, S78; on wheat, biolistics, S28; on wheat, genetics, 773; on wheat, partial resistance in lines, 198

Pumpkin

- fruit rot, cover cropping systems, S158

— fruit rot and edema, cropping systems, S21

- fungicides and cover crops, host resistance, S158 
Punja, Z. K., 1381

Pyrenophora spp.

$-P$. teres $=$ on barley, telomere analysis, other methods, S55

$-P$. tritici-repentis, on wheat: cultivar reactions, S27; epidemiology in Himalayas, 248; forensic pathology, 144; phenotypic diversity, North Dakota, S3; population genetic analysis, global collection, 1144; races 1 and 2, resistance, 172

Pyricularia grisea, on turf, rice defense-related genes, S49

Pythium spp.: on bean, resistance gene and molecular markers, S64; in container media, compost sources, suppression, 306; on creeping bentgrass, North Carolina, 962; soil compaction and crop monoculture, molecular study, S59; soil solarization, South Carolina, S76; on sugar beet, biocontrol with Lysobacter enzymogenes, 701; sugarcane, herbicide effect, soil microbes, 220; survey in South China, S43; on tomato, biopesticides, S38

-P. aphanidermatum: on bell pepper, net carbon gain, growth effect, 354; on cucumber, rockwool medium, 808

-P. irregulare, species boundary, AFLP analysis, 1489

Qin, G. Z., 69

Quadrat variance and size, clump size ratio, 452

Quarantine, international shipment of pathogens, S52

Quarantine inspection, seedborne fungi, ICRISAT, S74

Raaijmakers, J. M., 1325

Rabbinge, R., 439

Rademaker, J. L. W., 1098

Ragozzino, A., 420

Rahman, M., 1381

Rainfall, radar-estimated, risk forecast, letter to editor, 25

Ralstonia solanacearum

- on eggplant, molecular study in Philippines, S59

— genomic analysis, biovar differences, S30

- on geranium: race 3 biovar 2, 136, S32; race 3 biovar 2, water effluent, S50

—race 3 biovar 2: genes root exudates, S20

-sequence analysis and factors, S26

-on tomato and geranium, bacteriophage for control, S86

Ran, L. X., 1349

Rao, R., 206

Rapeseed (see also Brassica napus and Canola)

- diseases of, micronutrients and growth regulators, S97

Rapoport, H. F., 368

Rasmussen, J. B., 1144

Raspberry

- mosaic diseases, virus universe, S39

-three viruses, characterization, S66

Reeser, P. W., 1256

Regulatory plant pathology, downstream effects, S130

Reid, C. L., 362

Rekha, A. R., 1472

Remphrey, W. R., 859

Ren, Z. L., 1266

Resistance

-Arabidopsis to rhizobacterial induction, salicylic acid, 1349

-barley and wheat to stripe rust, molecular mapping, 427

-Capsicum annuum to root-knot nematode, histology and phenolics, 158

- cucumber to disease, induced by disruption of flavonoid pathway, 114

-gene-for-gene: coevolution, 728; wheat tan spot, S134 gene-specific, basal defense and host responses, S132

-grape to Pierce's disease: stem and leaf populations, 44; symptom indices, 36

—induced, elicitors, 1368

-innate immunity, molecular deconstruction, S137

- maize to Maize stripe virus and Maize mosaic virus, plant hopper number relation, 600

- Medicago truncatula to Uromyces striatus, mechanisms, 153

- melon to downy mildew, quantitative trait loci mapping, 556

- molecular marker technology, Monsanto experience, S139

-nonhost: multi-layer concept in Aradidopsis, session, S137; simply-inherited components, S137

- nonhost pathogen, mutations in $\mathrm{ABC}$ transporter, S137

—partial, commercial products, $\mathrm{S} 122$

- pea to Aphanomyces euteiches, USA and France, 1287

—peanut to leaf spot, transcripts, 381

-Phaseolus vulgaris: to Bean common mosaic virus and Bean common mosaic necrosis virus, 499; to bean leaf crumple, single dominant gene, 819; to white mold, oxalates, 292

-Populus spp., parasite-specific, nonhost resistance, 779

- strawberry to anthracnose, octoploid cultivar, 405

- sunflower to Sclerotinia sclerotiorum, trait loci analysis, 834

- sweet corn to Northern corn leaf blight, 85

- tobacco to fungi, pokeweed protein role, 206

- tomato to: begomoviruses, Bangladesh, 1472; Tomato spotted wilt virus, genetic engineering, 800; Xanthomonas campestris, race T1 strains, 519

- watermelon to Watermelon mosaic virus, inheritance and aphid transmission, 840

- wheat to: leaf rust, cultivar genetics, 773; leaf rust, partial, 198; tan spot, races 1 and 2, 172

Retropathology, disease for control of weeds, S125

Reviewers, acknowledgment, 4

Reynaga-Peña, C. G., 480

Reynaud, B., 600

Rheeder, J. P., 275

Rhizobacteria

—fungal pathogens inhibited by, isolation, S62

- growth-promoting, effect on tobacco diseases, $\mathrm{S} 50$

Rhizoctonia spp.: on azalea, container-grown, S21; binucleate, biocontrol of cotton leaf spot and damping-off, 1030; on roses, new anastomosis groups, 784

$-R$. solani: arom gene, transcriptional regulation, S56; on bean, nonpathogenic binucleate Rhizoctonia isolate, relation, 345; in container media, compost sources, suppression, 306; on cowpea, field tests, S102; mycovirus, genetic diversity, S18; on vegetables, teleomorph in New York, S37

Rhododendron, Phytophthora ramorum systemic fungicides, S96

Rhodotorula glutinis, biocontrol agent, patulin in stored apples, 127

Rice

- antifungal peptides, characterization, S159

-bacterial leaf blight, yield and quality, S57

-blast: avirulence gene, 768; avirulence genes, cultivar specificity, 640; defense genes, molecular approach, S16; epidemiology-related phenotypes, light, S57; Mn relation, S19; MST11 gene, S54; resistance genes, S108; resistance genes, floods, S175

-Cochliobolus miyabeanus and Magnaporthe grisea, defense mechanisms, 1248

- host-parasite interactions, functional genomics, S48

-Magnaporthe grisea, quantification, S9

-nematodes, bacterial endophytes for control, S79

— panicle blast, microclimate, 433

- sheath blight, transgenes and resistance, S117

- sheath blight and panicle blight, resistance breeding, S91

Rice, C., 1116

Riggs, R. D., 890

Risser, G., 405

Rizzo, D. M., 587

RNA, non-coding, plant response, S123

Rodoni, B., 420

Rönicke, S., 834

Rosa spp., root and stem rot, Rhizoctonia, anastomosis groups, 784

Rose black spot, chemical control, S112

Rossbach, U., 1098

Rossi, M. P., 1316

Rossing, W. A. H., 328

Rots, secret life, session, S136

Rotylenchulus reniformis

- abamectin sensitivity, S28

-on cotton, Pochonia chlamydosporia for control, 890

Rouxel, T., 1061

Ruiz-Herrera, J., 480

Rush, C. M., 25

Saaijer, J., 852

Sackett, K. E., 983, 992

Sacks, E. J., 519

Sacristán, S., 827

Saillard, C., 541

Sakaue, D., 737

Salicylic acid, binding protein 2 and plant immunity, S55

Salinity, tolerance, rapid blight disease, S83

Sameshima, T., 1137

Sandlin, C., 961

Sasanelli, N., 339

Satellite panicum mosaic virus

- capsid protein insertion, epitope display, S86

-replication and systemic movement, analysis, S115

Sawyer, S., 549

Schäfer, P., 528

Scherm, H., 108

Scheuerell, S. J., 306

Schiavi, M., 800

Schisler, D. A., 626

Schmale, D. G., III, 472

Schneider, R. W., 257

Scholes, J. D., 1294

Schultz, M. H., 1098

Schwartz, H. F., 918

Schwartzburg, K., 964

Sclerotinia spp., carpogenic germination, S113

$-S$. homoeocarpa, on turf: fungicide sensitivity, Ohio, S49; fungicides in North Carolina, S104

$-S$. minor: on peanut, transgenic lines, S83; populations in Texas, $\mathrm{S} 41$

$-S$. sclerotiorum: adenylate cyclase gene, analysis, S51; on bean, breeding nursery in Oregon, cover photo, March; on bean, epidemics, S86; on bean, resistance evaluation, $\mathrm{S} 86$; on canola, field response, $\mathrm{S} 13$; on dry bean, epidemic modeling, S24; on dry bean, weather relation in North Dakota, S163; host pathway for compatibility, S136; insertional mutagenesis, transformation, S108; on lentil, genetic diversity, S108; on lettuce, biocontrol with Coniothyrium minitans, S85; sclerotial development, protein kinase A, 397; sclerotial parasitism by Coniothyrium minitans, $\mathrm{pH}$ effect, S67; on soybean, lignin effect, S165; on 
sunflower, quantitative trait loci analysis, 834; transformation with fluorescent protein gene, $\mathrm{S} 23$

Sclerotium rolfsii

-endo-polygalacturonase, S20

-sclerotium formation, genes, S102

- on wheat and peanut, Oklahoma, S174

Scortichini, M., 1316

Secale cereale, nematode infection, hydroxamic acids, 1116

Seem, R. C., 1445

Segarra, J., 728

Séguin, A., 114

Seguin, P., 345

Seong, K., 744

Septoria albopunctata, on blueberry, survival analysis, 108

Serratia marcescens, on cucurbits, strain pathogenicity, S63

Setosphaeria turcica, on maize, light-regulated genes, S29

Shackel, K. A., 581

Shah, D. A., 472, 1405

Shaner, G., 198

Sharma, R. C., 248

Shaw, B., 965

Shi, A., 964

Shirouzu, K., 1209

Shishido, M., 1072

Shoresh, M., 76

Shrestha, S. M., 248

Shtienberg, D., 1200, 1279, 1412

Silvar, C., 1423

Singh, D. P., 528

Singh, P. K., 172

Sinorhizobium meliloti

-functional genomics platform, analysis, S94

— genome project management, applications, S94

Sivasithamparam, K., 1061

Skelsey, P., 328

Sledge, M., 1112

Slininger, P. J., 626

Smedsgaard, J., 1021

Smilanick, J., 963

Soil fumigants, Liatris production, drip applied, S34

Soil microbiology

- diversity and pathogen invasion, activity suppression, S45

- species diversity in organic and conventional farms, S11

Soilborne pathogens, soil suppressiveness, mixed and single crop effect, 1325

Soilborne wheat mosaic virus, genome, analysis, S96

Solanum tuberosum (see also Potato)

- aspartic proteinases, antimicrobial activity, S69

-epidemic development, host diversity effect, 328

Sorghum

- diseases in Deccan plateau of India, S74

-ergot: non-persistence in Mississippi, S152; prediction models, S113; rainfall and disease forecast, letter to editor, 25

- fumonisins, in grain, S74

-Fusarium spp., millet isolate comparison, 275

- grain mold, defense response genes, S151

Soto-Estrada, A., 751, 942

Soucaze, O., 158

Souche, S., 227

Soybean

—Asian rust: Alabama, S97; kudzu host, Florida, S40

—bacterial seed inoculation, yield effect, S162

- Cercospora leaf spot, purple seed stain, vegetative compatibility groups, 257

-cyst nematode: crops for management, S164; linkage map, S75; parasitism proteins, S108; resistance, marker-assisted selection, S139; satellite image intensity and yield using geostatistics, S162; virulence genes, Ror gene group, 186; yield factors, S164

- diseases and insects, Nebraska Crop Surveillance Network, S109

-DNA extracts, soil and beetle comparisons, S33

-foliar fungicides, yield, S176

-frogeye leaf spot, distribution in north central USA, S161

-fungal infection, ergosterol as fungal indicator, S114

-fungicide seed treatment, Arkansas, S176

-Fusarium spp., monitoring by DNA array hybridization, S59

-Fusarium solani, quantification with PCR, S47

-leaf extract phytotoxicity, Fusarium solani, S60

-myclobutanil, disease control, S78

—northern stem canker, maturity groups, S161

-Phialophora gregata, growth and yield effects, S164

-Phytophthora root and stem rot: field trials in South Dakota, S18; partial resistance, S70

-Pythium damping-off and root rot, resistance and Rps 1k gene, $\mathrm{S} 90$

-Rhizoctonia solani, seed treatments, Ontario, $\mathrm{S} 114$

-rust: alternative hosts in overwintering, S144; analysis in South America, S23; Brazilian strategy, S144; disease model, S165; epidemiology, kudzu and soybean hosts, S24; extension response, S144; flusilazole for control, S65; fungicide control, overview, S144; fuzzy logic system, 1122; infection rate, logic system, S53. myclobutanil effect, S77; outbreak in Brazil and South Africa, S23; peptide technology for management, S144; protein identification, S144; Sclerotinia sclerotiorum, soybean genotypes, S164; seed decay, incidence in midsouthern USA, S175; spore trajectories and pathways in USA, S54; sudden death, detection and quantification, S162; surveillance and visual assessment, S26; systemic disease resistance, beta-amino-butyric acid, 961; systemic fungicides, S65; urediospore deposition efficiency, S60; USA response, S144; virus survey, North Dakota, S164

Soybean dwarf luteovirus, aphid vector, dwarfing and yellowing, $\mathrm{S} 22$

Soybean dwarf virus, nucleotide sequence, S25

Soybean mosaic virus

- elicitors and virulence, S39

-resistance genes and alleles, S123

Spatial analysis, patterns and indices, 874

Special sessions

-biology of plant pathogens, S120

—diseases of plants, Fusarium head blight, S123

- epidemics affect people, S129

- epidemiology/ecology/environmental biology, S127

-flowers, unique habitat, S128

-Fusarium-induced diseases, tropical, perennial crops, S124

- history of plant virology, S121

-molecular/cellular plant-microbe interactions, S132

- oak wilt, origin and spread of pathogen, S126

- partial resistance to disease, $\mathrm{S} 122$

- plant disease loss, risk assessment, S131

— plant disease management, S137

-risk prediction and regulation, S130

— virus genetics, S122

Sphaeropsis sapinea, on pine, symptomatic shoots, S30

Spinach

- seedborne pathogens, chlorine and hot water seed treatments, S41

-white rust, weather-based advisory program, S22

Spink, J., 62
Spiroplasma spp.

$-S$. citri, spiralin, lectin binding, insect vector, 541

-S. kunkelii: on corn, Argentina, S34; plasmid, nucleotide sequence, adhesin, S168

Springer, P. S., 480

Squash leaf curl virus, Squash mild leaf curl virus comparison, host range, $\mathrm{S} 14$

Srinivasan, R., 25

St.-Arnaud, M., 345, 867

Stagonospora spp.

-S. avenae, molecular sequencing, S106

$-S$. nodorum, on wheat: aggressiveness in Ohio,

S27; genetic mapping of toxin, seedling resistance, S62; host selective toxin, S32

Stanosz, G. R., 608

Stea, V., 339

Stead, D. E., 1316

Steinberg, C., 1391

Steiner, U., 233

Stemphylium botryosum, on spinach seed, Cladosporium variabile comparison, $\mathrm{S} 41$

Stenger, D. C., 1217

Stenotaphrum secundatum, gray leaf spot, population structure, Georgia, 463

Stevenson, J. F., 36

Stevenson, K. L., 463

Stone, J. K., 1256

Stotz, H. U., 292

Strawberry

-anthracnose, resistance inheritance, 405

-chlorotic fleck, new Closterovirus, S105

-Colletotrichum crown rot, fungicides, S69

-fruit rot, postharvest, control, S82

-leather rot: chemical control, S12; fungicides for, S87

- phytoplasma taxon, Lithuania, S160

- soil management system, fungus dynamics, S57

Strawberry latent virus, plant and insect virus link, S105

Streptomyces sp.: antifungal activity, in soil, S47; on potato, diversity, S109

$-S$. scabies, on potato, green manure and crop sequence effect, 178

Striga spp., on cereals, rhizosphere organisms, S126

$-S$. gesnerioides, genetic structure and host analysis, Florida, 1166

$-S$. hermonthica, on wheat, Africa, 1294

Stringfellow, W., 965

Struck, C., 153

Sturhan, D., 1308

Su, W.-C., 533

Subbotin, S. A., 1308

Sugar beet

-Cercospora leaf spot, disease-monitoring thresholds, factors, 269

- cyst nematode, survival factors, 339

- powdery mildew, perfect stage in Wyoming and Montana, S162

-Pythium damping-off, biocontrol with Lysobacter enzymogenes, 701

_rhizomania, Rz gene, S91

-Verticillium wilt, potato rotation, S13

Sugarcane

-Pythium root rot, herbicide effect, soil microbiology, 220

-red rot, molecular characterization, S151

Sugarcane yellow leaf virus, Florida, spread, S150

Suh, S.-C., 1248

Sukno, S., 965

Sullivan, D. M., 306

Sunflower

- Sclerotinia root, stem, and head rot, trait loci analysis, 834

- Sclerotinia stalk rot, inoculation method, S163

Suppressive soil, mixed and single crop effect, 1325

Surujdeo-Maharaj, S., 1301 
Sutton, J. C., 354

Sutton, T. B., 92

Svanella-Dumas, L., 420, 617

Swanson, J. K., 136

Sweetpotato

- begomoviruses, breeding lines, S38

-Rhizopus soft rot, postharvest, S27

Swings, J., 1098

Symbiosis, Muscador spp., tropical trees, S138

Taipe, M. V., 1412

Takamatsu, S., 1137

Tall fescue, Bipolaris leaf spot, biocontrol with Lysobacter enzymogenes, 701

Tanacetum cinerariaefolium, foliar dieback, epidemic description, 648

Tang, J., 963

Tans-Kersten, J., 136

Tatum, K., 701

Tavella, L., 800

Teaching, learning styles, formats and media, S23

Tenllado, F., 894

Tenuta, M., 28

Teraoka, T., 1209

Termorshuizen, A. J., 1325

Thayer, C. L., 92

Thébaud, G., 1453

Theobroma cacao (see also Cacao)

-witches'-broom: black pod, relations, 1301; leaf interaction, 101; model system, S156

Thevenin, J.-M., 1301

Thomma, B. P. H. J., 1374

Thon, M., 965

Thorpe, D. J., 316

Tian, S. P., 69

Tilletia spp., secondary sporidia, epidemiology, 961

-T. indica: teliospore germination and basidiospore production, chemical effects, S35; teliospores, tillage effect, S3; on wheat, recovery in Texas, S64; on wheat, teliospores, Arizona, S3

Timko, M. P., 1166

Timmer, L. W., 241, 512

Tobacco

-downy mildew, resistance, South America, S116

-fungal pathogens, resistance from pokeweed protein, 206

-mold, population in Caribbean and Central America, S10

- spotted wilt: in field vegetation, S9; plant source effect, S9; strip till effect, S68

- target spot, fungicides, S159

Tobacco curly shoot virus

-on Nicotiana benthamiana, symptoms, cover photo, August

- symptoms intensified by DNA $\beta, 902$

Tobacco mosaic virus

- auxin response, disease pathway, S135

-double helix, Rosalind Franklin, S121

Tobacco streak virus, on hibiscus, detection in Florida, S59

Tomato

-Bacillus spp., mulch and spray effect, S73

-bacterial canker, resistance loci, proteomic analysis, $\mathrm{S} 122$

-bacterial speck, phytohormones and phytotoxin, S106

-bacterial spot, race T1 strains, resistance, 519

-bacterial wilt: Guatemala, S3; integrated management, S140

-begomovirus: resistance, nucleotides and whiteflies, 1472; sequence analysis, Nile and Mediterranean Basins, 549; Sultanate of Oman, 962

- cacao witches'-broom effect, symptoms, S171

- Capsicum chlorosis virus, new vector in Thailand, 659

_crown and root rot, saline irrigation, 1438 -fungicide-timing program, model programs, S170

-Fusarium wilt: biocontrol efficiency of $F u$ sarium, 1072; validamycin A, validoxylamine A, foliar spray, 1209

- gray mold rot and Salmonella contamination, biofumigation, S31

-late blight, greenhouse management, S8

— pith necrosis, Turkey, S93

- potato virus Y, tuber necrotic strain, S114

- powdery mildew, gene expression detection, PCR, 1137

-Pythium disease, biopesticides in greenhouses, S38

-Rhizoctonia solani and Meloidogyne incognita, methyl iodide effect, S151

-root knot and wilt, rhizobacteria, S97

-root-knot nematode, abamectin seed coating, S53

- soil fungal communities and land management, S113

- tospovirus, new from Iran, 852

-water infiltration, factors, S64

-witches-broom, histology and physiology, S65

Tomato bushy stunt virus

- on Nicotiana edwardsonii, resistance, S135

-nuclear localization, protein P22, session, S134

- plant nucleoprotein complex, infectivity, S77

- silence suppressor, siRNA binding, S45

Tomato golden mosaic virus, sequence elements, expression in protoplasts, S101

Tomato spotted wilt virus

—glycoprotein, virus acquisition inhibited by, S166

-isolates from North Carolina and California, molecular characterization, S75

$-N$ gene sequences, engineered resistance, 800

-on peanut, cultivar incidence, S69

-on tobacco: chemical sprays for, S157; managing thrips, S68

Tomato yellow leaf curl virus

—on pepper, dead-end host, 1089

- post transcriptional gene silencing, S1

Tospovirus

-multiple infections, detection with transcription PCR system, 166

-on tomato, new from Iran, 852

Toth, I. K., 1462

Toyoda, H., 1137

Tracy, M., 744

Tranzschelia discolor, on peach, initial colonization, 942

Traore, D., 1391

Tredway, L. P., 463, 962

Trichoderma spp., on cocoa, endophytic association, S5

-T. asperellum, on cucumber, systemic resistance, jasmonic acid/ethylene signaling pathway, 76

-T. atroviride: glucosaminidase regulation, $\mathrm{S} 19$; heavy metal sequestration potential, S67

-T. harzianum, fungivorous nematode, model, S55

$-T$. virens: on cotton, proteinaceous elicitor, S25; gene analysis and biocontrol, S111

Triky-Dotan, S., 1438

Tsaltas, D., 965

Tsuda, S., 166

Tsuge, T., 241

Turechek, W. W., 679

Turfgrass

- gray leaf spot, genetic structure of populations, Georgia, 463

Turnip crinkle virus, on Arabidopsis:

-race elements of hosts and pathogens, S135

— signaling, S2

Typhula ishikariensis, on winter wheat, PCR assay, S75

Tzanetakis, I. E., 1043
Uchida, J. Y., 316, 965

Uddin, W., 966

Uga, H., 166, 192

Ullrich, C., 362

Ulocladium atrum, biocontrol of Botrytis on cyclamen, 439

Umaharan, R., 1301

Umbellularia californica, leaf infections, S4

Uncinula necator

-on grape, germplasm collection, S169

-spore production, genes, S107

Uncinuliella australiana, on crape myrtle, molecular identification, S176

Uromyces spp.

-U. appendiculatus, on bean: Andean gene pool, resistance, S80; origin of diversity, S161; resistance genes, molecular markers, S80; variability in fields, S163

-U. striatus, on Medicago truncatula, resistance mechanisms, 153

Usami, T., 1072

Ustilago spp.

-U. maydis: on Arabidopsis thaliana, nonnatural host, 480; basidiomycete-specific pathogenicity determinant, S55; on corn, gall induction, S33; on maize, plant and fungal gene analysis, S73; sporulation, S33

-U. phrygica, on grasses, biocontrol for medusahead, S8

Utsuzawa, S. 737

Vaiciunas, J., 1237

Vaira, A. M., 800

Valesia, G., 672

van Bruggen, A. H. C., 1325

Vandecasteele, C., 608

Vandemark, G. J., 499

van den Berg, N., 965

van den Bosch, F., 632

van der Werf, W., 328, 439

van Elsas, J. D., 808

van Enckevort, P., 962

van Loon, L. C., 1349

van Ruiten, J., 962

van Schie, J., 962

van Vliet, A., 962

Vasey, R. A., 1294

Vauterin, L., 1098

Vecchiati, M., 800

Vecchione, A., 672

Vegetables, seed industry, terminology and abbreviation codes, 961

Venturia inaequalis, on apple:

—epidemic progress, model, 1001

- predictor evaluation, curve analysis, 679

Verreet, J. A., 269

Verticillium spp., on lettuce, response variation, S106

-V. albo-atrum, on alfalfa, DNA content and disease severity, S56

$-V$. dahliae: microsclerotia, swine manure effect, 28; on potato, green manure and crop sequence effect, 178

Viljoen, A., 965

Vintal, H., 1279

Viruses

- density gradient centrifugation, Myron Brakke, S121

- design, Crick and Watson to Caspar and Klug, S121

-host gene expression, analysis, S135

- hosts in Cuba, S154

-insect transmission, paint brushes and Parafilm, S121

-Resistance gene-mediated defense, signaling, S122

-RNA silencing and immunity, plant homolog role, $\mathrm{S} 135$

—RNAi, plant pathology history, S121 
- serology, Helen Purdy Beale, S121

- trichoviruses, capilloviruses, and foveaviruses, polyvalent detection, 617

- vaccines in plants, vectors for, S51

Viveros, M., 708

Vogler, A., 834

Voisin, R., 1151

von Bodman, S., 965

Vovlas, N., 368

Vujanovic, V., 867

Walcott, R. R., 413

Walker, M. A., 36, 44

Wallace, L. D., 972, 1363

Walsh, D., 1368

Walsh, K., 1462

Walters, D. R., 1368

Wang, K., 890

Wang, T. C., 1122

Wang, X., 1341

Wang, Y.-Y., 433

Watermelon (see also Cucumis melo and Melon)

-bacterial fruit blotch, biocontrol, 413

-Fusarium wilt: green manure and resistance effects, S160; resistance and inoculum density, S118

- soil microbial communities, Rio Grande Valley, S35

— vine decline and fruit rot, Florida, S89

Watermelon mosaic virus, on Cucumis melo, resistance inheritance, aphid transmission, 840

Watermelon silver mottle virus, Calla lily chlorotic spot virus in serogroup, 1482

Weeds, invasive species, containment facility, S166

Wen, K., 345

West, J. S., 933

Wheat

- barley yellow dwarf, yield in Alabama, S12

-blast, Paraguay, S152

—breeding programs, integrating MAS, S139

—deoxynivalenol, Pyraclostrobin, S43

- disease survey in Texas, Landsat Thematic Mapper imagery, S50

-Fusarium crown rot, PCR for measurement, S26

-Fusarium graminearum: maize comparison, S124; microsatellite genotyping, S139; mycotoxin accumulation, 1397; resistance, markerassisted selection, session, S139

-Fusarium head blight: biocontrol with Cryptococcus nodaensis, 626; breeding and DNA markers, S124; deoxynivalenol relation, S81; epidemics, ascospore role, $\mathrm{S} 124$; incidence in Ohio, 1049; inheritance in Abura, S49; integrated management, S88; modeling, 1225; modeling epidemics, S71; outbreak in Brazil, S23

— gene silencing, virus-induced, S123

- glyphosate resistance, rust control, S29

-Gibberella zeae, spore deposition patterns, 472

- Karnal bunt, regulatory programs, S137

-leaf rust: genetics in cultivars, 773; partial resistance in lines, 198

-Phaeosphaeria nodorum, seedborne, population in New York, 300 —phytoalexin, induced metabolite, S95

- powdery mildew: cultivar mixture as management, S21; plant metabolites, chromatography, S172

— puroindolines, antifungal activity, S104

—rhizosphere, Pseudomonas putida effect, S5

-root rot, resistance, $\mathrm{S} 112$

— scab, virulence genes, insertional mutagenesis, 744

-Septoria leaf blotch, fungicide resistance, 933

- Septoria tritici blotch, isolate-specific resistance genes, 664

- spot blotch: defense mechanisms, host genotypes, 528; and tan spot, epidemiology, Himalayas, 248

-Stagonospora nodorum: signaling, S136; and Pyrenophora tritici-repentis, seedling reactions, S28

- -stem rust, resistance to African isolates, S49

—-Striga hermonthica, Africa, 1294

- stripe rust: disease gradients in field, 983; epidemic, spread velocity, 972, 1363; foliar and spike resistance inheritance, S65; Louisiana, S175; resistance gene, diagnostic markers, 1266; resistance genes, molecular mapping, 427

-take-all: epidemiology and chemical control, 62; focal spread, S111

- $\tan$ spot: forensic pathology, 144; gene-forgene, S134; global collection, population genetic analysis, 1144; races 1 and 2, resistance, 172

Wheat and barley, Fusarium head blight, agriculture effect, S123

Wheat streak mosaic virus

- on spring wheat compared to winter wheat, S56

-on wheat, nitrogen relation, remote detection, S50

Wickland, A. C., 587

Wiggins, B. E., 178

Wilcox, W. F., 679, 1445

Wilson, C., 648

Withagen, J. C. M., 1001

Wolf, P. F. J., 269

Wood decay

-brown rot, calcium and oxalate regulation, S172

- oak and pine, brown rot fungi, S78

- sulfuryl fluoride and methyl bromide toxicity, S105

Workneh, F., 25

Wyatt, S. D., 1037

Xanthomonas spp., strain taxonomic framework, 1098

-X. arboricola, on stone fruits, origin in Western Europe, 1081

-X. axonopodis: on citrus, avirulence gene, S91; on citrus, detection, wind driven splash, S11; on citrus, identification methods, S25; on citrus, strain enumeration and discrimination, 1333; on onion, pathovar relatedness, 918; on soybean, hypersensitivity, Thailand, 962

-X. campestris: on crucifer, dioxygenase gene, $\mathrm{S} 84$; on geranium, resistance, S117; on tomato, race $\mathrm{T} 1$ strains, resistance, 519; on zinnia, cercosporin degradation, oxidoreductase, S102
-X. oryzae, on rice: PCR for detection, S51; type III effectors, host genes, S115

Xiao, C. L., 572

Xie, Y., 902

Xiphinema spp.

-X. americanum, on Secale cereale, hydroxamic acids, 1116

-X. index: on grape, soil survival, 1151; Grapevine fanleaf virus vector, detection, RNA extraction, 262

$\mathrm{Xu}$, J.-R., 744

Xu, X.-M., 874

Xylella fastidiosa

-on almond: disease progress patterns, S37; genotypes in California, 708; insect vectors, S16; leaf scorch, cover photo, June; strains and colony morphology, S18

-on Chenopodium quinoa, chlorosis, S14

— calcium and magnesium effect, 963

- cysteine residues, pathogenic importance, 962

- glutathione, calcium relation, 963

-on grape: biocontrol, S44; hosts in California, $\mathrm{S} 8$; movement in hybrids, $\mathrm{S} 18$; polygalacturonase, pathogenicity, S90; resistance, symptom indices, 36; stem and leaf populations, 44

- on grape and almond: detection, S19; pathogen detecting system, S61

-on grape and citrus, hemagglutinin effect, S54

-hosts, Texas, S10

-on mulberry, oleander, and grape, California, S41

- on Nicotiana tabacum, California, S31

—on oak, New Jersey, S36

-planktonic and biofilm growth, on media, 963

Yaegashi, H., 640

Yamaguchi, I., 1209

Yamamoto, H., 241

Yamamoto, M., 241

Yang, J., 965

Yang, S.-S., 433

Yang, W., 519

Yang, X. B., 1122

Yao, J., 136

Yarden, O., 397

Yasuda, N., 768

Yedidia, I., 76

Yeh, S.-D., 533, 1482

Yermiyahu, U., 1438

Yin, L.-F., 640

You, B.-J., 533

Yuen, G. Y., 701

Zamani, A., 284

Zasada, I. A., 1116

Zeller, K. A., 275, 961

Zhang, H. Q., 1266

Zhang, H. Y., 1266

Zhang, J. X., 859

Zhang, S., 626

Zheng, Y., 708

Zhou, X., 902

Zhu, S. F., 566

Zhu, W., 965

Zhu, Y.-Y., 433

Zini, M., 1316 


\section{Author Index of APS Annual, Special Sessions, and Division Meeting Presentations}

Aasheim, M., S27

Abad, G., S1

Abad, J., S1, S75

Abadias, M., S59

Abawi, G., S37, S169, S169

Abbas, H., S1

Abdelalim, F., S73

Abele, S., S129

Abhary, M., S1

Abou Ghanem-Sabanadzovic, N., S92

Abou-Zeid, N., S103

Abraitiene, A., S158

Abril, M., S2

Ac, C., S2

Acevedo, M., S99, S161

Achor, D., S89

Acosta-Leal, R., S2

Acton, T., S55

Adams, D., S72

Adams, M., S3

Adams, S., S111

Adaskaveg, J., S30, S70, S140

Adedotun, A., S2

Adhikari, T., S3

Adkins, S., S2, S2, S46, S59, S89

Afanasenko, O., S17

Afunian, M., S3, S59

Aguiar, J., S105

Ahlstrand, G., S10

Aigbe, S., S6

Aime, M., S14

Ajwa, H., S139

Al-Ahmad, H., S126

Albertazzi, F., S40

Aldwinckle, H., S24, S110

Alexander, B., S76, S76, S130

Alexander, H., S102

Alexander, N., S124

Aley, P., S85

Alezones, J., S151

Alfano, J., S32, S34, S38, S48, S103

Alhudaib, K., S3

Ali, S., S3

Alibhai, M., S29

Allen, C., S3, S20, S30, S32, S147

Allen, R., S45

Allen, T., S3, S3, S14

Allende-Molar, R., S4

Allorent, D., S93

Almanza, L., S31

Al-Niemi, T., S104

Alonso, M., S153

Al-Saleh, M., S69

Alvarado, A., S31

Alvarenga, N., S77

Alvarez, A., S33, S107, S107

Ambourn, A., S127, S161, S161

Amerson, M., S18

Amsellem, Z., S126

Anacker, R., S158

Anandhakumar, J., S4

Andersen, G., S5

Anderson, J., S47, S49, S123, S124

Anderson, L., S4

Anderson, T., S59

Andrews, D., S55

Andrews, J., S4, S68
Andrie, R., S134

Anfoka, G., S1

Angel, C., S135

Anikster, Y., S165

Annamalai, M., S2

Anoop, V., S124

Appel, D., S41, S127

APS Collections and Germplasm Committee, S4

Aranguren, M., S154

Araya, C., S161

Archibald, D., S171, S173

Armstrong, R., S34, S66

Arul, J., S173

Asciutto, K., S82

Ash, J., S57

Ashley, R., S172

Asvarak, T., S134

Atibalentja, N., S75

Avant, J., S47

Avila-Adame, C., S89

Avila-Quezada, G., S149

Awasthi, R., S97

Awele, O., S2

Aylor, D., S85

Aysan, Y., S93

Babadoost, M., S4, S47, S81, S146

Babalola, O., S126

Babbitt, R., S116

Bacetty, A., S5

Backman, P., S24, S65, S69, S138, S138, S156, S156, S157, S168, S171, S171

Bacon, C., S5, S5, S138

Badillo-Ponce, G., S149

Bae, H., S5

Bai, J., S95

Bailey, B., S5, S69, S157, S171

Bailey, K., S83

Baker, C., S2, S46, S89

Baker, J., S79

Baker, S., S134

Bakker, P., S5, S5, S5, S145

Bakkeren, G., S28

Balaji, B., S135

Balbalian, C., S92

Balcerzak, M., S124

Balci, S., S158

Balci, Y., S155, S158

Baldauf, P., S6

Baley, J., S29

Baliji, S., S6

Balint-Kurti, P., S6

Ballard, K., S132

Balogh, B., S6, S33

Baltensperger, D., S40

Bandla, M., S2, S85

Bandyopadhyay, R., S6, S58, S74, S74, S125

Barabote, R., S133

Barak, A., S105

Barasubiye, T., S59

Barata da Silva, G., S84

Barber, B., S10

Barbosa, M., S149

Barnes, C., S6, S166

Barney, B., S103

Baron, J., S13

Barras, F., S133

Barreto, R., S71
Barrientos, V., S151

Barta, A., S25

Barthe, G., S24, S24, S52, S90

Barthelson, R., S114

Bartz, J., S7, S64

Basinal, L., S79

Bates, G., S7

Batista, L., S154

Batlle, A., S153, S153

Batzer, J., S7, S7, S26, S66, S101

Bau, H., S7

Baudoin, A., S7

Baum, T., S45, S103, S108

Baumann, K., S7, S14, S46

Baumgartner, K., S8

Beattie, G., S18

Becker, C., S131

Becker, D., S153, S166

Becker, O., S77

Becktell, M., S8

Bedell, J., S109

Begum, S., S132

Behle, R., S26

Bekal, S., S75

Bélanger, R., S95, S171, S172

Bell, A., S8

Bell, B., S155

Belmar-Diaz, C., S149

Belmont, R., S151

Belzile, F., S171

Bender, C., S40, S106

Benitez, M., S38

Benson, D., S174

Benson, E., S15

Benzina, F., S39

Berardi, R., S68, S85

Beretta, J., S52

Beretta, M., S24, S24

Bergelson, J., S47

Berger, P., S15, S50, S130

Bergstrom, G., S72, S127

Berkett, L., S8, S8

Berland, P., S102

Bernardy, M., S31

Berner, D., S8, S14, S24, S155, S156, S156, S168

Bernier, L., S84

Berruyer, R., S9

Berry, D., S110, S111

Bertrand, P., S9, S9, S68

Besler, B., S69

Bextine, B., S9

Bhaskara Reddy, M., S100, S100

Bhat, R., S9

Bhatia, J., S60

Bhattarai, E., S26

Bienapfl, J., S9, S72

Biggs, A., S156

Bigirimana, S., S129

Bilgi, V., S10, S53

Bin, L., S132

Bird, G., S10, S10

Bird, J., S7, S46

Bissegger, M., S171

Blachere, F., S2

Black, M., S10

Blaedow, R., S10, S127

Blaine, M., S176

Blanchette, B., S94

Blanchette, R., S94
Blanco-Meneses, M., S10

Blodgett, J., S10

Blok, W., S62

Bloomberg, J., S174, S175

Blouin Bankhead, S., S11

Bluhm, B., S11, S112

Bo, L., S11

Boa, E., S153

Boal, R., S113

Bock, C., S11, S11, S11, S12, $\mathrm{S} 12$

Boehm, M., S12, S49, S49, S93, S117

Bok, J., S96

Bolton, M., S23

Bond, J., S161

Bonde, M., S144

Bonman, J., S47

Bootten, T., S76, S76

Boratynski, T., S3

Borneman, J., S77

Bost, S., S12, S12

Boston, R., S44

Bottner, K., S57

Bouchard, R., S87

Boudreau, M., S12

Bounds, R., S161

Bovitz, J., S94

Bowden, R., S58

Bowen, K., S12, S39

Bowers, J., S158

Bowersox, V., S6

Bowman, L., S123

Boyette, C., S125

Boza, E., S13

Bradeen, J., S166

Bradley, C., S10, S13, S36, S53, S86

Bradshaw, T., S8, S8

Brandt, A., S123

Brannen, P., S13

Brantner, J., S13

Branzanti, B., S90

Braverman, M., S13

Breeden, T., S78

Brena-Becerril, A., S151

Brenneman, T., S17, S174, S176

Brewer, M., S56

Bridges, W., S119

Britton, K., S99

Brlansky, R., S90, S91

Brodhagen, M., S13

Brooks, B., S120

Brooks, S., S14

Brown, J., S7, S14, S20, S42, S46, S67, S70, S150, S151

Brown, L., S14

Brown, R., S19

Brown-Guedira, G., S14, S139

Browning, M., S104

Bruckart, W., S14, S155, S156

Bruening, G., S14, S31

Bruton, B., S63, S89

Bryan, H., S151

Bryant, J., S162

Buck, J., S14, S88

Buckley, K., S11, S94

Buddie, A., S125

Buell, R., S89

Bullians, M., S130

Bulluck, R., S15, S50 
Bunckle, A., S31

Bunkers, G., S29

Burch, K., S12

Burger, M., S107

Burkhart, C., S15, S15, S168

Burlakoti, R., S3

Burnett, F., S30

Burrows, M., S15

Buruchara, R., S15, S64

Bussey, K., S15

Butler, L., S104

Buzayan, J., S14

Byrne, D., S76

Cabrera, A., S53

Cabrera, J., S16, S37

Cacciola, S., S62

Caceres, J., S62

Cadle-Davidson, L., S107, S169

Cai, G., S88

Caillaud, M., S15

Calabro, J., S16

Caldo, R., S132

Caldwell, P., S23

Camberato, J., S83

Camilli, K., S41, S127

Camp, A., S38

Camp, M., S21, S59

Camp, S., S100

Campbell, B., S56

Campbell, H., S39

Campbell, L., S91

Candole, B., S16

Canteri, M., S16, S144

Canteros, B., S154

Caragea, P., S162

Caramori, P., S16

Carbone, I., S16, S18, S85, S89

Carnevali, G., S42

Carpane, P., S34

Carpenter, J., S92

Carr, T., S135

Carrillo, G., S132

Carrillo, M., S16

Carroll, R., S155

Carta, L., S141, S141

Carter, M., S63

Cartwright, R., S13, S118, S175, S176

Caruso, F., S17, S17, S78

Castell-Miller, C., S17

Castillo, M., S138

Castro, A., S17

Castro, C., S150

Catlin, N., S17

Caviedes, M., S40

Cavin, C., S155

Cawly, J., S135

Center, T., S87

Ceri, H., S30

Cervino, J., S120

Chaluvadi, S., S132

Chalwe, A., S72

Chamberlain, H., S17

Chambers, J., S60

Chang, C., S18

Chang, P., S18

Charkowski, A., S73, S95, S115, S133

Charlton, N., S18

Charudattan, R., S120

Chase, T., S18, S161

Chassaigne, A., S151

Chellemi, D., S2, S113
Chen, C., S18, S109

Chen, H., S103

Chen, J., S16, S18, S19, S37

Chen, S., S164

Chen, T., S111

Chen, W., S108, S108, S111

Chen, X., S5, S19, S45, S115

Chen, Y., S7, S18, S114

Chen, Z., S19

Chenault, K., S20, S174

Cheng, M., S19, S19, S45

Cheng, Y., S171

Cheng, Z., S108

Chet, I., S111

Chiang, Y., S55

Chicas, M., S40

Chinnasri, B., S19

Chitrampalam, P., S85

Choi, J., S63

Choi, Y., S20, S57

Choppakatla, V., S20, S174

Chorkowski, A., S82

Christ, B., S15, S15, S168, S172

Christianson, T., S74

Christopher, D., S19

Chun, W., S84

Chung, W., S57

Church, G., S113, S141

Cihlar-Strunk, C., S164

Citovsky, V., S135

Ciuffetti, L., S134

Civerolo, E., S14, S16, S18, S19, S31, S37, S61

Clark, C., S38

Clark, J., S176

Clark, W., S30

Clarke, B., S12, S42

Clement, D., S158

Clement, P., S98

Cleveland, T., S19

Clifford, J., S20

Clinton, W., S29

Clough, S., S122

Cluck, D., S78

Coaker, G., S122

Cober, E., S114

Cogal, A., S88

Cohen, M., S20, S20, S67

Cohen, S., S94

Colburn, G., S20

Coleman, M., S99

Collins, A., S20, S21, S158

Colyer, P., S94

Comstock, J., S150

Concibido, V., S139

Connelly, F., S9

Connor, K., S112

Conway, W., S21, S59

Cook, A., S11, S12, S80

Cook, B., S174

Cook, C., S78

Cooke, L., S67, S116, S167

Cooksey, D., S41

Cooley, D., S21, S168

Cooper, B., S144, S144

Cooper, L., S21

Cooperband, L., S165

Copes, J., S60, S61, S61

Copes, W., S21, S21, S60, S60, S61, S61

Corley, J., S103

Correll, J., S13, S98, S118, S175

Cortesi, P., S171
Cortina, G., S150

Costa, H., S41

Coto, O., S153

Cotton, J., S21

Cotty, P., S47, S150

Counce, P., S175

Courtois, B., S17

Cowger, C., S21

Cox, J., S16

Cox, K., S22

Coyle, D., S99

Coyne, D., S80

Cram, M., S99

Cramer, C., S130

Crawford, M., S88

Creager, A., S121

Creasap, J., S22

Crisosto, C., S79, S79

Crosby, K., S22, S80

Crosby, T., S57

Croslin, J., S57

Cross, P., S128

Crouch, J., S42

Crowley, M., S68

Crozier, J., S125

Crunkleton, E., S155

Cruz B., J., S150

Csinos, A., S16

Cubeta, M., S18, S21, S101

Cueto, J., S153

Cueto, R., S154

Culbreath, A., S175

Culver, J., S135

Cuomo, C., S118

Curry, K., S2

Czymmek, K., S53

D’Arcy, C., S23

Dai, W., S108

Daleo, G., S69

Dally, E., S157, S168

Damann, K., S19

Damasceno, C., S52

Damicone, J., S22, S102, S152

Damsteegt, V., S22, S22, S94

Danesh, D., S162

Dang, P., S37, S58

Dangott, L., S25

Danielson, G., S164

Datnoff, L., S100, S172

Daub, M., S102

Daughtrey, M., S8, S168

Davelos Baines, A., S35, S66

Davey, J., S155

Davis, A., S37

Davis, E., S45, S61, S61, S103, S108, S113

Davis, J., S10

Davis, R., S50, S57, S106, S117, S156, S157, S159, S160, S160, S168, S169

Dawson, W., S58

De Boer, S., S65

de la Cerda, K., S113

De La Cruz, Y., S30

De la Cruz-Cevallos, L., S151

de la Torre, M., S83

de Loza-Macias, M., S151

de Silva, A., S23, S107

De Wolf, E., S71

Deahl, K., S31

Dean, R., S118

Deboer, G., S78

Deeken, R., S23

Del Ponte, E., S23, S23, S23

del Rio, L., S13, S24, S53, S86, S163

del Valle, N., S154

Delaney, T., S137

DeMarsay, A., S24, S155

Demers, A., S24, S156, S168

Dennis, M., S15

Denny, T., S32

Deom, C., S73

Dernoeden, P., S169, S170, S171

Derrick, K., S24, S24, S52

DeSantis, T., S5

Desjardins, A., S124, S124, S146

Devall, M., S112

DeVerna, J., S78

DeVries-Paterson, R., S50

Dewdney, M., S24, S156

Dias, A., S23, S24

Diaz-Huerta, L., S97

Dickman, M., S136

Dickstein, E., S25

Diers, B., S139

Dillard, H., S172

Dilley, J., S6

Dill-Macky, R., S82, S92

Dinesh Kumar, S., S122, S135

Ding, M., S120

Ding, X., S132

Ditmore, M., S25

Dixon, P., S128

Djavaheri, M., S5

Djonovic, S., S25

Dolan, M., S130

Dolezal, W., S142

Dollet, M., S153

Dombroski, A., S25, S25

Domier, L., S25, S75

Donaldson, R., S18

Dong, R., S45

Donohue, C., S86

Doohan, D., S73

Dorrance, A., S70, S144

Doshi, R., S85

Double, M., S127, S155

Douches, D., S163

Douet, V., S133

Douhan, G., S4

Douhan, L., S4

Draper, M., S144, S163

Dreher, T., S106

Driever, G., S79

Droby, S., S141

Druffel, K., S79

Dry, I., S107

du Preez, E., S23

du Toit, L., S41, S41, S57

Du, L., S116

Duan, Y., S26, S32

Dubin, J., S8

Dufault, N., S26

Duffie, W., S175

Duncan, R., S26

Dunkle, L., S29, S134

Dunlap, C., S26

Duque, P., S32

Duttweiler, K., S26

Dyer, A., S26, S26 
Edmunds, B., S27, S44

Edwards, M., S27

Edwards, P., S9

Egel, D., S52

Eggenberger, A., S39

Eggers, J., S158, S161, S166

Ehret, G., S68, S85

El Lissy, O., S144

Elliott, D., S76, S76

Elliott, G., S172

Ellis, M., S60, S76, S87, S87, $\mathrm{S} 128$

Elmer, W., S27, S169

Elphinstone, J., S33, S50

El-Sherif, M., S109

Endres, M., S123

Engle, J., S27, S27, S28

Engledow, A., S28

English, J., S144

Esh, A., S95

Eskalen, A., S28

Eskandari, F., S14, S156

Esker, P., S128, S165

Esquivel, J., S8

Estevez de Jensen, C., S162

Ethredge, W., S175

Eubanks, M., S21

Evans, H., S5

Evans, T., S95, S155, S159

Everett, K., S28

Everts, K., S21, S52, S118, S158, S158, S160

Expert, D., S133

Fabry, S., S97

Falacy, J., S36

Fan, J.-B., S135

Fare, D., S60, S60, S61, S61

Faria, R., S16

Faris, J., S32, S62

Farmerie, W., S33

Fasi, A., S47

Faske, T., S28

Fayad, A., S90

Feasel, J., S117

Feldstein, P., S14

Fellers, J., S14, S28

Feng, P., S29

Fenn, P., S98

Ferencak, M., S117

Ferguson, B., S85

Ferguson, G., S31

Ferguson, L., S57

Fernandes, J., S23

Fernandez, G., S57

Fernández, R., S82

Fernandez-Pavia, S., S149, S149, S149

Ferrandino, F., S27, S169

Ferrin, D., S75

Fery, R., S102

Fessehaie, A., S29, S29, S129

Festa, R., S42

Fichtner, E., S29

Filgueira, J., S153

Filippi, C., S26

Firko, M., S131, S142

Fisher, A., S29

Fitzgerald, C., S158

Flaherty, J., S29

Fleischer, S., S34

Fletcher, F., S63

Fletcher, J., S147

Flett, B., S88

Floes Cruz, Z., S30
Flood, J., S125, S125

Flore, J., S58, S170

Flores O., A., S150

Flores, Z., S32

Flowers, J., S30

Flynn, A., S130

Foglia, G., S30

Foote, P., S100

Forouhar, F., S55

Forster, H., S30, S140

Foster, K., S62, S171

Foster-Hartnett, D., S162

Fought, L., S174, S175

Fraaije, B., S30

Fraire, S., S30, S31

Francis, D., S122

Francis, M., S16, S31

Francl, L., S71

Franco-Lara, L., S153

Fraser, D., S83

Fravel, D., S31

Frederick, R., S63

Freeman, M., S18, S37

Freitas, P., S31

French, C., S31

French, R., S89

French-Monar, R., S31

Frick, H., S159

Fridman, E., S55

Friel, C., S32

Friesen, T., S28, S32, S55, S62, S101

Fry, B., S32

Fry, W., S8, S32, S32, S88

Fu, Y., S83

Fu, Z., S32

Fucikovsky, L., S32

Fucikovsky-Zak, L., S97

Funnell, D., S32

Gabriel, D., S26, S32, S86

Gadoury, D., S33, S107, S169

Gafni, A., S81

Gaitan, S., S153

Galbraith, D., S114

Gale, L., S162

Galehr, J., S96

Gallegos M., G., S150

Gallian, J., S100

Galloway, H., S36, S37, S81

Gao, X., S33, S33, S47, S162

Garay-Serrano, E., S149, S149

Garbelotto, M., S9, S41, S62, S90

Garber, B., S175

Garces Araujo, L., S84

Garcia, M., S8, S8

García-Chapa, M., S153

Garcia-Pedrajas, M., S33, S33, $\mathrm{S} 35, \mathrm{~S} 73$

Gardea, A., S149

Gardiner, E., S112

Gardner, D., S66

Garner, D., S79, S79

Garry, C., S28

Gatyeni, P., S88

Gavilanes-Ruiz, M., S83

Gay, D., S6

Gaya, A., S105

Gbur, E., S94

Ge, Z., S34

Geddens, R., S34, S65, S65

Gee, C., S169

Geiser, D., S98, S169, S173

Geister, R., S2
Gelvin, S., S132

Geppert, R., S161

Gera, A., S2

Gergerich, R., S101

Gerhardt, S., S104

Gerik, J., S34

German, T., S166

Gerson, U., S81

Gevens, A., S34, S162

Gibb, K., S128

Giblin-Davis, R., S141

Giese, H., S162

Giesler, L., S93, S109, S118, S144

Gigot, J., S34

Gilbertson, R., S26

Gilchrist, D., S133

Gildow, F., S22, S22, S34, $\mathrm{S} 121, \mathrm{~S} 157$

Giles, K., S45

Gill, B., S14, S123

Gillen, A., S100

Gilroy, S., S53

Gimenez, M., S34

Gitaitis, R., S29, S35

Glasner, J., S133

Gleason, M., S7, S7, S25, S25, S26, S66, S101, S102

Gleddie, S., S124

Glenn, A., S5, S79, S118

Glenn, D., S11, S35

Glover, K., S56

Goddard, T., S85

Godoy, C., S16, S23, S144

Goh, Y., S161

Gold, S., S33, S33, S35, S55, $\mathrm{S} 73, \mathrm{~S} 102$

Goldman, S., S117

Gomez-Alpizar, L., S89

Gómez-Leyva, J., S151

Gong, J., S60

Gonzales, O., S35

González, A., S151

Gonzalez, C., S28

Gonzalez, E., S33

González, V., S153

Gonzalez-Losa, M., S74

Gonzalez-Ramos, J., S35

Goodell, B., S78

Goodman, R., S165

Goodwin, P., S3, S17, S132

Goodwin, S., S35

Goodwine, W., S140

Goraczniak, R., S36

Gorbet, D., S175

Gordon, T., S32, S83, S124

Goreau, T., S120

Gottschalk, K., S155, S158

Gottwald, T., S11, S11, S12, S36, S80, S129

Gould, A., S36

Gould, S., S94

Grabau, E., S83

Graef, G., S118

Graessle, S., S96

Grafton, K., S10, S86

Graham, A., S100

Graham, J., S35, S113, S140

Gramacho, K., S65, S171

Granc, G., S162

Grau, C., S165

Gray, S., S6, S15, S82, S121

Greaves, N., S83

Greene, S., S38, S38

Grefer, D., S117

Gregoire, M., S36

Gregorich, E., S59

Gremillion, S., S175

Gressel, J., S126

Greve, L., S90

Grichar, J., S69

Griffey, C., S65

Griffin, M., S36

Griffin, R., S131

Grimm, C., S53

Grisham, M., S36

Gross, D., S87, S109

Groth, D., S73, S91, S117

Grove, G., S36, S37, S81

Groves, R., S16, S18, S19, S37, S61

Grube, R., S106

Grunden, E., S64, S164

Grunwald, N., S37, S37, S108, S129, S149, S149

Grybauskas, A., S88

$\mathrm{Gu}$, Y., S56

Guan, J., S131, S162, S164

Gubler, R., S44

Gubler, W., S28

Guevara, M., S69

Gugino, B., S37, S169, S169

Guilhabert, M., S54

Guiltinan, M., S65, S69, S156, S157, S171, S171

Gulya, T., S163

Gumpertz, M., S11

Gundersen, B., S34

Guo, B., S37

Guo, M., S34, S38, S48, S103

Guo, R., S135

Guo, Y., S108

Gutarra, L., S85, S85

Gutierrez Chapin, L., S38

Gutierrez, D., S38

Gwinn, K., S38, S38

Haddad, F., S63

Hadwiger, L., S39, S40

Hagan, A., S39

Hajeri, S., S39

Hajimorad, M., S39

Hajj Moussa, E., S16

Halbrendt, N., S173

Halgren, A., S39

Hallett, S., S126

Halterman, D., S62

Hameed, K., S39

Hamel, P., S112

Hamelers, B., S62

Hamelin, R., S39

Hamilton, G., S36

Hammerschmidt, R., S47, S163, S163

Hammond, J., S2

Hammond, R., S40, S158, S160

Hane, D., S164

Hanson, L., S40

Hanson, S., S99

Harakava, R., S24

Harikrishnan, R., S163

Harlan, B., S42

Harley, S., S40

Harlin, K., S6

Harmon, P., S40 
Hartman, G., S33, S60, S60, S162

Hartman, J., S30

Hartney, S., S40

Harveson, R., S40, S40

Hatfield, R., S165

Hau, B., S105

Hausbeck, M., S34, S42, S161, S162, S163

Hauschild, R., S97

Hay, E., S170

Hay, F., S128

Hayden, K., S41

Hayes, R., S106

Haynes, K., S15, S15, S168

Hayslett, M., S41

He, G., S37

He, S., S137

Heatherly, L., S175

Hebbar, P., S159

Hed, B., S169, S173

Hedrich, R., S23

Heidel, T., S77

Heijne, B., S43

Henn, A., S92

Henry, M., S41

Henson, R., S13, S86, S163

Herbel, M., S14

Hernández C., F., S150, S150

Hernandez-Martinez, R., S41, $\mathrm{S} 113$

Hernandez-Perez, P., S41, S41

Hernández-Zepeda, C., S42

Herre, E., S138

Herrmann, R., S159

Hershman, D., S144

Hess, N., S27, S42

Higginbotham, L., S120

Highland, H., S42

Hilburn, K., S163

Hilf, M., S58

Hill, A., S40

Hill, J., S39

Hill, S., S42, S163

Hillman, B., S36, S42, S42

Hinton, D., S5

Ho, H., S43

Hoberg, A., S164

Hogg, A., S26

Hoke, S., S88

Holb, I., S43, S43, S43

Holbrook, C., S37

Hollier, C., S131

Hollingsworth, C., S43, S43, S165

Hollister, E., S163

Holm, R., S13

Holmes, G., S27, S44, S52

Holmes, K., S5

Holmes, R., S44

Honea, G., S38, S38

Hong, C., S44, S45, S55, S159, S159

Hong, S., S91

Hooker, D., S123

Hoover, K., S104

Hopkins, D., S29, S44, S44

Horn, B., S16

Horst, L., S77

Hou, B.-H., S137

House, B., S94

House, E., S111

Howell, C., S44

Hoy, M., S38

Hoyt, D., S148
Hsieh, J., S134

Hsieh, Y., S45

Hsu, H., S7

Hu, J., S44, S45, S159

$\mathrm{Hu}, \mathrm{S} ., \mathrm{S} 11, \mathrm{~S} 45$

Huang, G., S45

Huang, J., S113

Huang, L., S14, S123

Huang, Q., S32, S116

Huang, Z., S135

Huber, D., S19, S45, S67, S166

Hüberli, D., S90

Huettel, R., S45

Hughes, T., S56

Hulbert, S., S137

Hunger, R., S20, S45, S174

Hunnicutt, L., S58

Hunt, T., S109

Hunter, D., S3

Hunter, W., S58, S58, S72

Hurtado-Gonzales, O., S92

Hussey, R., S45, S103, S108

Hwang, J., S46

Hyder, N., S46

Iamauti, M., S77

Idris, A., S7, S14, S42, S46, S70, S150, S151

Igmatov, A., S160

Impullitti, A., S64

Imrie, G., S88

Indira, S., S74

Ineson, J., S125

Inglis, D., S34

Inman, A., S46

Inman, S., S46

Irey, M., S46

Iriki, N., S75

Isard, S., S26

Islam, S., S4, S47

Ito, M., S75

Ivors, K., S37, S90

Jacinto-Hernández, C., S152

Jackson, A., S121, S134

Jackson, E., S47

Jackson, T., S33, S47, S162

Jacobs, J., S47, S63

Jacobsen, B., S162

Jahn, C., S133

Jaime, M., S47

Jaime-Garcia, R., S47, S150

Jakob, K., S47

Jakobek, J., S16

Jambunathan, N., S170

Jamir, Y., S38, S48

Janczur, K., S73

Janisiewicz, W., S21, S48, S59

Jean, G., S32

Jeffers, S., S46, S48, S87, S119

Jeger, M., S43

Jellison, J., S78, S172

Jeong, B., S32, S48

Jeong, J., S118

Jeremiah, S., S129

Ji, P., S140

Jia, H., S163

Jia, M., S48, S108, S118

Jia, Y., S13, S48, S48, S108, S112, S118, S132, S175

Jianfa, B., S132

Jie, F., S135

Jifon, J., S22

Jiménez D., F., S150, S150

Jimenez Gasco, M., S49
Jiménez, J., S48

Jimenez, P., S119

Jimenez-Diaz, R., S49

Jimenez-Gasco, M., S173

Jin, H., S94

Jin, Y., S49, S49, S49, S49, S167

Jirka, A., S72

Jo, Y., S12, S49, S49

Jochua, C., S161, S163

Johnson, C., S50, S130, S157, S159

Johnson, D., S76

Johnson, G., S164

Johnson, J., S6

Johnson, K., S50, S100, S128

Johnston, A., S124

Johnston, R., S26

Johnston, T., S116

Joly, D., S39

Jomantiene, R., S50, S106, S156, S157, S159, S160, S168, S169

Jonawiak, J., S104

Jones, A., S64, S171

Jones, D., S25, S50, S50, S50, S91, S99

Jones, J., S6, S25, S31, S42, S69, S91, S140

Jones, M., S130

Jones, W., S156

Jordahl, J., S86

Jordan, S., S51

Joshi, R., S38, S51

Juárez, R., S151

Juncal, J., S153

Jurick, W., II, S51

Juzwik, J., S10, S41, S127, S127, S158, S161, S161, S166

Kachroo, A., S2

Kachroo, P., S2

Kadooka, C., S106

Kahn, M., S94, S94

Kaiser, M., S162

Kaiser, R., S143, S174, S175

Kamas, J., S10

Kaminski, J., S169, S170

Kanaan-Atallah, Z., S51

Kaneshiro, W., S107, S107

Kanetis, L., S51, S140

Kang, H., S2

Kang, M., S51, S57

Kang, S., S53, S65, S156, S171

Kankanala, P., S9

Kanyuka, K., S3

Kaplan, D., S15, S50, S130

Karasev, A., S51

Karimi Jashni, M., S87

Katan, T., S162

Katsvairo, T., S104

Kawakami, A., S75

Kayim, M., S52

Kazemi, H., S87

Keen, N., S82, S115, S117

Keinath, A., S29, S52, S76

Kelemu, S., S52

Keller, J., S15

Keller, N., S13, S96

Kelley, B., S52

Kelso, S., S124

Kemerait, R., S175, S176

Kemmitt, G., S78

Kenerley, C., S25, S41, S111

Kennelly, M., S33, S127

Kenney, M., S52

Kernaghan, G., S88

Kessel, G., S52, S98, S98

Khan, M., S53

Khot, S., S13, S53

Kidwell, K., S29

Kiewnick, S., S53, S53

Kim, H., S53

Kim, J., S56, S57

Kim, K., S53, S54, S82

Kim, M., S116

Kim, S., S54, S54

Kim, T., S55

Kim, Y., S54, S54, S54

Kingsley-Richards, S., S8

Kinkel, L., S82

Kinter, M., S122

Kinyua, M., S49

Kirk, W., S110, S111, S116, S163, S167

Kirkpatrick, B., S54, S90

Kirkpatrick, M., S176

Kirkpatrick, T., S94, S175

Kistler, H., S162, S163

Kitner, M., S105

Kleinhenz, M., S73

Klessig, D., S2, S55

Kliejunas, J., S78

Klingeman, W., S36

Klopfenstein, N., S116

Klosterman, S., S55

Kluepfel, D., S55, S67, S80, S110

Kniskern, J., S47

Knudsen, G., S55

Knudson, M., S108

Koehler, K., S7

Koehn, A., S112

Koeller, W., S143

Koepke, T., S104

Köhl, J., S52

Kohn, L., S47, S92, S108

Kolmer, J., S78

Kolomiets, M., S33, S75

Kolte, S., S97

Kong, H., S156

Kong, P., S44, S55

Koprowski, H., S51

Kosta, K., S137

Kraus, R., S175

Krause, C., S77

Kroken, S., S134

Kruger, W., S122

Krupa, S., S6

Kuldau, G., S64, S138, S171, S173

Kulemeka, B., S2

Kumar, D., S55

Kumar, S., S57

Kung, Y., S7

Kunkel, D., S13, S103

Kunta, M., S97

Kurle, J., S162, S163

Kuroki, M., S75

Kurtzman, C., S59

Kushnir, L., S81

Kuykendall, L., S72

Kyde, K., S104

Kyllo, D., S138 
Laflamme, G., S170, S173

Laguna, G., S34

Lai, Z., S55

Lakshman, D., S56

Lalancette, N., S62, S171

Laluk, K., S56

Lambert, K., S33, S47, S75, S162

Lambert, S., S128

Lambrecht, P., S40

Lamour, K., S34, S37, S92

Lampe, D., S9

Landa, B., S49

Langham, M., S56, S164

Langor, D., S39

Langston, D., S29, S52, S176

Lanier, L., S175

Larkin, K., S85

Larkin, R., S56, S77, S139

Larsen, R., S56

Larson, T., S124

Lashomb, J., S36

Latin, R., S12

Laux, P., S116

Lauzon, C., S9

Laviña, A., S153, S153

Lawrence, A., S92

Lawrence, C., S136

Layne, D., S22, S93

Lazo, G., S56

Leach, J., S17, S132, S137

Leandro, L., S57

Leavitt, G., S57

Lebas, B., S76, S76

Lebreton, L., S111

Lee, B., S51

Lee, C., S72, S86, S133

Lee, D., S51, S57

Lee, F., S13, S118, S175, S175

Lee, I., S57

Lee, K., S57, S57, S57

Lee, L., S58, S58

Lee, R., S39, S86

Lee, S., S52, S58

Lee, Y., S14

LeGare, D., S13

Legg, J., S129

Lehman, B., S58, S58, S170

Leininger, T., S112

Leisso, R., S99

Leslie, J., S6, S58, S58, S74, $\mathrm{S} 125, \mathrm{~S} 148$

Lessl, J., S129

Leung, H., S17, S132

Leverentz, B., S21, S59

Lévesque, A., S15, S78

Lévesque, C., S59, S59, S59, S59

Levy, L., S11, S15, S50, S80, $\mathrm{S} 130$

Levy, M., S19

Lewandowski, D., S59

Lewis Ivey, M., S59, S73

Li, B.-Y., S134

Li, H., S59

Li, J., S135

Li, S., S33, S60, S60, S60, S116, S162

Li, W., S15

Li, X., S60, S60

Li, Y., S60, S60, S61, S61

Lima, M., S71

Lin, H., S16, S61

Lin, M., S48, S118

Lindbo, J., S121
Linderman, R., S37, S61, S61

Ling, H., S62

Ling, K., S61

Linscombe, S., S91

Linzer, R., S62

Lipka, V., S137

Lipps, P., S27, S27, S28, S71, $\mathrm{S} 81, \mathrm{~S} 81$

LiPuma, J., S28

Lira-Saldivar, R., S150, S150

Little, C., S35, S66, S151

Littler, D., S120

Littler, M., S120

Liu, B., S16

Liu, C., S56

Liu, J., S170

Liu, L., S33

Liu, Q., S117

Liu, Z., S62, S62

Llauger, R., S153

Locke, J., S77

Lokaj, G., S62

Long, D., S132

Long, R., S158

LoParco, D., S95

Loper, J., S100, S144

López C., R., S150

Lopez, J., S8

Lorang, J., S134

Lorbeer, J., S95

Louws, F., S45, S57

Lozano, J., S62

Lozoya, E., S31

Lozoya-Saldaña, H., S149, S149

Lu, A., S159

Lu, G., S26

Lu, S., S62, S109

Lucas, J., S30, S143

Ludwig, J., S37

Luis, M., S154

Lumpkin, S., S99

Lumsden, R., S159

Luna-Paez, A., S151

Lunden, J., S36, S37

Lundquist, J., S10

Luo, G., S63

Luo, M., S37

Luo, Y., S63

Luster, D., S22, S22, S63

Lydon, J., S156

Lynch, S., S29

Lynn, K., S37

Ma, B., S63, S170

Ma, M., S114

Ma, Z., S63, S63, S68, S85, S117

MacDonald, J., S115

MacDonald, W., S127, S155, S156, S158

Machado, J., S43

Mack, R., S104

Macnab, A., S170, S170

MacRae, I., S43

Madden, L., S27, S71, S76, S81, S81, S87, S87, S128

Madriz, K., S40

Maffia, L., S63, S63, S71

Magarey, R., S131, S144

Magill, C., S151

Mahaffee, W., S36, S37, S81

Mahasneh, A., S39

Mahovic, M., S7, S64

Mahuku, G., S15, S52, S64, S64
Mahungu, N., S72

Mailhot, D., S64

Majeau, J., S84

Malinoski, M., S158

Malkus, A., S159

Mallik, I., S74

Maloney, S., S94

Malvick, D., S64, S164, S166

Mangravita-Nova, A., S76

Manjunath, K., S91

Manning, V., S134

Mansfield, M., S64, S171

Maples, H., S64

Mara, J., S15

Marasas, W., S74, S88, S125

Marban-Mendoza, N., S151

Marchand, G., S171

Marcon, A., S65, S65

Marek, S., S65, S107

Marelli, J., S65

Marelli, J.-P., S156, S171

Mark, W., S72

Markell, S., S65

Markwordt, J., S85

Marois, J., S40, S64, S104

Maroon-Lango, C., S2

Marques, L., S30, S65

Marques, M., S65

Marquez, M., S85

Marra, R., S171

Martienssen, R., S109

Martin, K., S113

Martin, M., S66

Martin, R., S39, S66, S101, S105, S105, S106

Martin, S., S83, S83

Martin-Duvall, T., S57

Martinez, E., S66

Martinez, J., S134

Martinez, N., S35

Martinez-Espinoza, A., S55, S66, S66

Massman, J., S66

Mastro, V., S104, S105, S105

Matheron, M., S67, S85

Mathew, F., S67

Mathieson, T., S78

Matthews, M., S99

Matthies, I., S87

Matveeva, E., S160

Mauromoustakos, A., S175

Mavrodieva, V., S11

Maximova, S., S65, S171, S171

Maxwell, D., S1

Mazzola, M., S20, S20, S67

McBeath, J., S19, S67

McCartney, C., S67

McClean, A., S55, S67

McCormick, S., S124

McDonald, G., S116

McDonald, J., S142

McDonald, S., S171

McDonald, V., S68

McEwen, D., S74

McGrath, M., S68, S68, S143, S171

McGriff, E., S68

McInnes, B., S65

McKee, B., S68

McKellar, M., S98

McKemy, J., S15

McLaughlin, N., S59

McLeod, A., S32

McMahon, M., S63, S155

McManus, P., S68, S78, S85

McMillan, J., S65

McMillan, R., S151

McMullen, M., S123

McNellis, T., S170

McPherson, R., S68

McSorley, R., S109

McSpadden Gardener, B., S38, S51, S145

Meador, C., S69

Medrano, E., S8

Meinhardt, S., S32, S62

Meir, S., S126

Meister, G., S60

Mejia, L., S3, S138

Melcher, U., S63

Melnick, R., S69, S157, S171

Melouk, H., S20, S69, S69, S174

Melton, T., S101

Menard, R., S27, S42, S69

Méndez, M., S151

Mendieta, J., S69

Menge, J., S68

Mengiste, T., S136

Mengistu, A., S175

Menkir, A., S19

Mercado-Blanco, J., S5

Mercer, P., S67

Mercier, J., S31, S48, S141

Mertely, J., S69, S82

Meyer, S., S70, S160

Michael, J., S14

Michailides, T., S63

Mideros, S., S70

Midland, S., S113

Mika, J., S17

Miklas, P., S122

Mila, A., S70

Milgroom, M., S171

Miller, D., S164

Miller, J., S84, S123, S150

Miller, M., S22, S70

Miller, N., S70

Miller, S., S59, S73, S147

Miller, T., S9

Mills, K., S70

Milus, E., S65

Mirik, M., S93

Mirkov, T., S35, S71

Mironenko, N., S17

Mischke, S., S160

Mishra, P., S56

Mitchell, T., S118

Mitchum, M., S108

Miyanishi, M., S96

Mizubuti, E., S63, S71, S71

Mlikota Gabler, F., S71, S90

Mlotshwa, S., S123

Mmbaga, M., S72, S95, S176

Moctezuma, H., S151

Mohamed, Z., S95

Molina, J., S71

Molineros, J., S71

Mollov, D., S164

Momol, M., S40, S140

Mondal, S., S71, S96

Monfort, W., S175

Montelione, G., S55 
Moreno-Valenzuela, O., S42, S74

Morgan, G., S121, S121

Morris, T., S135

Morrison, M., S59, S114

Mortimer, M., S94

Morton, J., S157

Mosquera, G., S9

Motteberg, C., S43, S43

Motteram, J., S30

Moyer, J., S1, S75

Mrema, F., S72

Msiska, Z., S157

Muchovej, R., S89

Mueller, D., S101

Mueller, J., S78

Mueller, T., S26

Muimba-Kankolongo, A., S72, S72

Mukalazi, J., S15

Mulholand, V., S33

Mullen, J., S97

Mullis, S., S35

Mulrooney, R., S155

Mundo-Ocampo, M., S151

Mundt, C., S147

Munkvold, G., S122

Munyaneza, J., S57

Muondo, P., S72

Murday, E., S171

Murolo, S., S90

Murphy, J., S21, S72

Murphy, P., S74

Murphy, S., S9, S72

Murphy, T., S72

Murray, D., S69

Murray, T., S75

Musson, G., S174, S175

Mwangi, M., S6, S125

Myers, K., S32

Myers, R., S175

Nadal, M., S73

Naidu, R., S73

Nakhla, M., S1, S73

Nanayakkara, U., S73, S172

Nandakumar, R., S73

Naranjo, M., S154

Nasser, W., S115

Nault, B., S34

Nava-Diaz, C., S73

Navarre, D., S2

Navarrete-Yabur, A., S74

Navi, S., S74, S74, S74

Navia, M., S64, S64

Nayudu, M., S11, S12

Neate, S., S58, S101

Nelson, B., S23, S74, S164, S164

Nelson, C., S139

Nelson, R., S132, S146

Nemchenko, A., S75

Nettleton, D., S132, S135

Neveu, B., S171

New, S., S1, S75

Ngugi, H., S75, S129

Niblack, T., S33, S47, S75, S162

Nie, J., S114, S114

Nielsen, C., S75

Nieto-Angel, D., S149

Nishio, Z., S75

Nita, M., S76, S128

Nitzan, N., S76

Niver, A., S12, S49
Njoroge, S., S76

Noe, J., S5

Noel, G., S75

Noh, T., S51, S57

Nolte, P., S84

Norman, D., S26, S32, S76

Ntawuruhunga, P., S129

Nunez, A., S63

Nutter, F., Jr., S128, S131, S162, S164, S165

Nutter, F., S131

Nwankma, U., S2

O’Donnell, K., S162, S173

O'Hern, C., S144

O’Neill, N., S160, S170

O'Reilly, K., S73

Obiero, H., S129

Ocamb, C., S70

Ochoa-Corona, F., S1, S76, S76, S130

Ojiambo, P., S128

Olanya, M., S77

Olarte, R., S90

Olatinwo, R., S77

Olaya, G., S77, S165

Oliver, R., S136

Olivera, P., S165

Olson, B., S77

Olson, M., S30

Olson, S., S140

Olson, T., S54

Omarov, R., S45, S77, S86, $\mathrm{S} 115, \mathrm{~S} 134$

Omer, M., S13, S77

Oña, I., S17, S132

Opina, N., S59

Ordonez, M., S78

Ortiz, S., S10

Ostrofsky, A., S78

Otaye, D., S107

Otrosina, W., S78

Otsyula, R., S64

Oudemans, P., S24, S78, S155

Ouellet, T., S124

Ouimette, D., S77, S78

Overton, B., S172

Overturf, K., S47

Owen, D., S72

Ownley, B., S36, S38, S38, S78

Ozuna, S., S97

Padgett, G., S175

Padgham, J., S79

Padmanabhan, M., S135

Padovanni, A., S65

Pagano, M., S69

Page, K., S103

Pagliaccia, D., S79

Pahalawatta, V., S79

Pair, S., S63

Palencia, E., S79

Palm, M., S15, S146

Palmieri, M., S151

Palou, L., S79, S79

Palumbo, J., S79

Pan, Y., S36

Pan, Z., S54

Pandelova, I., S134

Panella, L., S40

Pappu, H., S79

Paradell, S., S34

Park, E., S80

Park, S., S53, S55, S57, S80, S80
Parker, P., S11, S11, S12, S80

Parker, S., S80

Parra, G., S15

Parrish, M., S157

Partridge, D., S83

Pastor-Corrales, M., S80

Pasura, A., S172

Patnaikuni, M., S33

Patterson, C., S156

Paul, P., S81, S81

Paulitz, T., S4, S29

Pavan, W., S23

Pavon, C., S81

Payton, M., S20, S45, S174

Paz, Z., S81

Pedersen, J., S32

Pedersen, W., S166

Pedroza-Sandoval, A., S149

Peetz, A., S36, S81

Pelayo-Zaldivar, C., S149

Peltier, A., S165

Peña, I., S154

Peng, J., S135

Peng, Q., S82

Penman, L., S19

Penuela, S., S162

Pequenino, F., S72

Peralta, E., S153

Percich, J., S162

Pereira, R., S36

Peres, N., S69, S82, S82

Pérez, B., S82

Perez, C., S82

Perez, J., S97, S154

Pérez, R., S154

Perez-Hernandez, O., S24, S54, $\mathrm{S} 82, \mathrm{~S} 144$

Perry, K., S6, S121

Perry, R., S10

Peter, K., S82

Petersen, J., S83

Peterson, G., S3, S35, S83

Peterson, P., S83, S83, S83, S121

Pethybridge, S., S128

Phibbs, A., S25

Phillips, D., S60

Phillips, J., S1

Phipps, P., S83

Pichersky, E., S55

Pierson, E., S145

Pierson, L., S145

Pierzynski, J., S15

Pieterse, C., S145

Pilgeram, A., S126, S126

Pinckard, T., S41

Pitchay, D., S77

Pitman, R., S175

Pitt, W., S83

Pivonia, S., S165

Plasencia, J., S83

Ploetz, R., S125, S125

Plourde, K., S84

Poe, S., S130

Pokorny, J., S94

Polashock, J., S84

Polson, S., S120

Ponce de León, G., S149

Pond, E., S68

Poop, M., S176

Poplawsky, A., S84

Porchas, M., S67

Porter, D., S21

Porter, L., S84

Porter, P., S13, S164

Poston, D., S176

Poulton, N., S14

Poussier, S., S9

Powell, J., S52, S98

Powers, T., S141

Prabhu, A., S84

Pratt, R., S84, S87

Presting, G., S32

Pretorius, Z., S85

Price, E., S85

Price, J., S66

Priou, S., S85, S85

Proctor, R., S124

Proffer, T., S63, S68, S85

Pryor, B., S85, S91

Puente, M., S6

Puppala, N., S92

Purvis, M., S175

Putnam, M., S70

Py, B., S133

Qi, D., S86

Qin, Q., S106

Qu, X., S172

Quimby, P., S125

Rabbinge, R., S52

Rabinowicz, P., S109

Rai, M., S71

Ramadugu, C., S86

Ramasubramaniam, H., S24, S86

Ramette, A., S47

Ramirez, L., S138

Ramirez, P., S40

Ramirez-Cervantes, F., S151

Ran, L., S5

Randall, P., S96

Rangel, B., S39, S86

Rao, T., S74

Rasmussen, J., S10, S62, S86

Ravirala, R., S86, S133

Raya, D., S72

Rayamajhi, M., S87

Rayside, P., S100

Razavi, M., S87

Re, E., S14

Reap, J., S65

Rebollar-Alviter, A., S87, S87

Records, A., S87, S109

Reddy, C., S74

Reddy, J., S32

Reddy, M., S15

Reddy, R., S74

Redinbaugh, M., S87

Reed, E., S88

Reed, S., S95

Reed, T., S157

Reeleder, R., S88

Rees-George, J., S28

Refshauge, S., S11, S12

Reilly, C., S88

Rémus-Borel, W., S95, S172

Renick, L., S88

Restrepo, S., S88

Reverchon-Pescheux, S., S115

Rheeder, J., S88

Rice, C., S160

Richards, A., S152

Richardson, B., S116

Richardson, P., S44

Riley, R., S118 
Rinehart, T., S21

Rio, L., S67

Rioux, D., S173

Rioux, S., S59

Ristaino, J., S10, S11, S89, S89

Ritchie, D., S89

Rivas, M., S83

Rizzo, D., S4, S9, S29, S62, S72, S90

Robb, K., S110

Robbins, R., S141

Robert, L., S124

Roberts, D., S70

Roberts, P., S17, S31, S89

Robertson, N., S89

Rodríguez, A., S153

Rodríguez, M., S153

Rodríguez, R., S30, S153

Rodriguez-Alvarado, G., S149, S149

Rogan, D., S151

Rogers, J., S54

Rogers, P., S89

Rohde, W., S153

Rollins, J., S51

Romanazzi, G., S90, S90

Romero-Montes, G., S149

Romo, E., S70

Rooney-Latham, S., S28

Roose, M., S71

Roossinck, M., S123

Roper, M., S90

Rosas, J., S99

Rose, J., S52

Rosenberger, D., S21, S77

Rosenzweig, N., S90, S165

Rosseto, J., S77

Rossing, W., S98, S98

Rosskopf, E., S113, S115

Rosso, M., S90, S176

Rost, T., S99

Rotenberg, D., S165

Rothrock, C., S7, S90, S94, S102, S176

Rouviere, P., S84

Rowe, R., S13

Rowe-Lucas, N., S78

Roy, A., S90, S91, S142

Roy, G., S91

Roye, M., S20, S100

Royer, M., S144

Royer, T., S45

Rubio, T., S134

Rudd, J., S99

Rudrabhatla, S., S117

Runa, F., S91

Rupe, J., S90, S176

Rush, C., S3, S3, S50, S50, S64, S91, S99, S113

Rush, M., S73, S91, S117

Russell, M., S130

Russin, J., S161

Rutger, J., S48

Rutherford, M., S125

Ryan, D., S65

Rybak, M., S91

Rytter, J., S173

Sabanadzovic, S., S92

Sabaté, J., S153, S153

Sabo, F., S114

Saccardo, F., S79

Saddler, G., S33

Saftner, R., S21, S84

Sagaram, U., S92
Saghai Maroof, M., S70

Sahin, F., S93

Sahota, P., S61

Saito, K., S75

Salas, A., S85

Salas, B., S92

Salcedo, E., S153

Saleh, A., S58

Samac, D., S162, S165

Sams, C., S78

Samuels, G., S5

San Francisco, M., S86, S133

Sanchez Perez, A., S3

Sanchez, A., S10

Sanchez, D., S83

Sánchez, L., S151

Sanders, H., S35

Sanderson, P., S77

Sands, D., S125, S126

SanJuan, A., S83

Sankar, U., S87

Sanogo, S., S92, S92

Saraiva, R., S63

Sartorato, A., S93

Saucedo, M., S30

Saude, C., S92

Sauer, M., S87

Saunders, M., S92

Savary, S., S93

Savelle, A., S93

Saygili, H., S93

Schaad, N., S160

Schaafsma, A., S123

Schaefer, K., S97

Schafer, R., S111

Schauer, S., S123

Schell, M., S32

Scherm, H., S75, S93, S102, S103, S128, S129

Scheuerell, S., S37

Schiff, N., S112

Schilder, A., S51, S58, S58, S170

Schilling, J., S172

Schimelfenig, J., S93

Schisler, D., S26, S93, S117, S129

Schlub, R., S93

Schmale, D., III, S127

Schmidt, F., S144

Schmidt, M., S161

Schnabel, G., S15, S22, S43, S93

Schneider, K., S64

Schneider, R., S144

Schneider, S., S139

Schneider, W., S22, S22, S94, S157

Schneiderman, D., S124

Schoedel, B., S50

Schoelz, J., S135

Scholthof, H., S45, S77, S134

Scholthof, K., S86, S115

Scholthof, K.-B., S121

Scholz-Schroeder, B., S94, S94

Schroeder, B., S94

Schulz, M., S94

Schulze, D., S19, S166

Schwartz, H., S40

Schwehr, R., S174

Schwingle, B., S94

Sciumbato, G., S174, S176

Scofield, S., S123

Seay, J., S55

Sechler, K., S20
Seck, A., S137

Seebold, K., S35, S176

Seem, R., S24, S33, S107

Segura, G., S52

Seifert, K., S59

Seijo, T., S82

Seixas, C., S144

Semones, S., S46

Semtner, P., S157

Senesac, A., S96

Seyb, A., S95

Sh. Pekhtereva, E., S160

Sha, X., S91

Shabana, Y., S95

Shah, D., S34, S172

Shahjahan, A., S73

Shalaby, A., S95

Shallow, N., S95, S172

Shao, J., S157, S168

Sharapova, N., S162

Sharma, N., S15

Shaw, C., S151

Shearer, J., S120

Shephard, G., S88

Shepherd, C., S34, S66

Sherman, D., S22, S22, S94

Sherwood, J., S73, S104

Sheu, Z., S95

Shew, B., S12, S176

Shew, D., S101

Shi, A., S72, S95, S176

Shi, L., S134

Shi, Y., S117

Shiel, P., S15

Shiferaw, H., S135

Shih, D., S117

Shilts, T., S96

Shim, H., S51, S57

Shim, W., S20, S92

Shirako, Y., S96

Shishkoff, N., S20, S96, S96, S157, S160, S166

Sholberg, P., S96

Shortle, W., S172

Shuew, D., S45

Shulaev, V., S55

Shung, C., S101

Shwab, E., S96

Sikora, E., S97

Sikora, R., S53, S53, S79, S97, $\mathrm{S} 138$

Silva, F., S65

Silva, O., S16

Silva-Rojas, H., S97, S149, $\mathrm{S} 151$

Simard, M., S173

Sims, J., S151

Singh, M., S97, S175

Singh, P., S57, S57, S97

Singh, R., S49, S49, S97

Singh, S., S26

Singh, U., S97

Sipes, B., S19

Skantar, A., S141, S141

Skaria, M., S97, S97

Skelsey, P., S98, S98

Slininger, P., S93

Slinski, S., S98

Smallwood, E., S8

Smart, C., S88, S98

Smilanick, J., S71, S90, S140

Smit, E., S5

Smith, B., S2

Smith, D., S15, S99, S176

Smith, G., S120, S120

Smith, J., S94

Smith, L., S93

Smith, S., S65, S66, S78, S98

Smith, T., S72

Snook, M., S5, S5

Snover-Clift, K., S98

Soares, R., S144

Soehner, S., S65, S65

Solorzano, C., S166

Somers, D., S139

Somerville, S., S137

Son, M., S11

Soriano, E., S152

Souza, E., S112

Spaine, P., S99

Sparks, K., S45, S134

Speck, J., S1, S75

Spiegel, S., S2

Spiers, J., S60

Spinks, B., S176

Spotts, R., S16, S37, S77

Sprott, D., S124

St. Martin, S., S70

Stacey, G., S144

Stack, J., S15, S142, S145

Stamler, R., S99

Stanaland, D., S13

Stanghellini, M., S75, S79

Staniszewska-Goraczniak, H., S36

Staniulis, J., S160

Stanosz, G., S99

Staples, R., S28

Starner, V., S103

Starr, J., S28, S33

Steadman, J., S80, S99, S161, S163

Steddom, K., S50, S91, S99

Steenkamp, E., S125

Stefanelli, D., S10

Steffenson, B., S17, S101, S165

Stein, M., S137

Stevenson, J., S99

Stevenson, K., S35

Stevenson, W., S51, S89, S165

Stewart, C., S100

Stewart, E., S172

Stewart, F., S76

Stiles, C., S100

Stockinger, E., S122

Stockwell, V., S100, S128, S145

Stolze, J., S166

Stommel, J., S31

Stone, A., S22, S22, S94

Strange, R., S134

Strausbaugh, C., S100

Strem, M., S5

Stringfellow, B., S100, S100

Strobel, G., S138

Stromberg, E., S45, S159

Su, B., S67

Subbarao, K., S106, S113

Sudarshana, P., S55, S67

Suga, H., S162

Sugio, A., S115

Sugiyama, N., S17, S132

Sukno, S., S113

Sullivan, M., S101 
Sunter, J., S6

Susaimuthu, J., S101

Suslow, T., S31

Sutherland, A., S22

Sutton, D., S99

Sutton, T., S131

Sweat, T., S101, S134

Swoboda, C., S101

Syverson, R., S166

Szabo, L., S6, S28, S78, S118, S166

Sztejnberg, A., S81

Tabiki, T., S75

Takach, J., S102

Takahashi, Y., S61

Takenaka, S., S75

Taliaferro, C., S107

Tally, A., S77, S144

Tambong, J., S59

Tang, J., S76, S76

Tarnowski, T., S102

Tarr, D., S102

Tatalovi, N., S102

Tavantzis, S., S18, S56

Taylor, C., S94

Taylor, E., S7

Taylor, J., S102

Taylor, T., S102

TeBeest, D., S25, S71

Tedford, E., S140

Teixeira, H., S63

Temple, T., S100

Tenney, J., S7

Tenuta, A., S59

Tenuta, M., S70

Teran, H., S26

Termorshuizen, A., S62

Terre, S., S53

Thakur, R., S74

Thekke veetil, T., S25

Theu, M., S72

Thies, J., S102, S115

Thill, C., S164

Thomas, A., S1

Thomas, D., S74, S88

Thomas, S., S5

Thomas, T., S97

Thomashow, L., S11, S145

Thompson, D., S30, S103

Thompson, G., S72

Thompson, I., S166

Thorne, J., S89

Thornton, H., S103

Thurston, D., S109

Tian, D., S103

Tian, F., S38, S103

Tigner, T., S44

Timila, R., S172

Timmer, L., S17, S71, S96, S116

Tingle, C., S176

Tinker, N., S124

Tjosvold, S., S154

Tobiasz, M., S168

Todd, J., S175

Tofoli, G., S77

Tohamy, A., S103

Toler, J., S76

Tolin, S., S123

Tomaso-Peterson, M., S103

Tonapi, V., S74, S74

Tong, L., S55

Tooley, P., S74, S104

Torabi, M., S87
Trail, F., S124

Travis, J., S169, S173

Tredway, L., S104, S104

Trent, M., S152

Trevathan, L., S152

Tribus, M., S96

Trigiano, R., S60, S60, S61, S61

Tripathy, S., S37

Triplett, L., S104

Trout, T., S139

Trujillo, K., S104

Tsigbey, F., S104

Tsitsigiannis, D., S13

Tsukuhara, R., S16, S23

Tsygankova, S., S160

Tu, C., S11, S45

Tubajika, K., S104, S105, S105

Tumbalam, P., S111, S116, S167

Turechek, W., S82, S156

Turgeon, B., S134

Turini, T., S85, S105

Turner, R., S30

Turoop, L., S105

Tusiime, G., S59

Tuttle, A., S168

Tweddell, R., S173

Twieg, E., S50

Tyler, B., S37, S70

Tylka, G., S162, S164

Tzanetakis, I., S39, S66, S101, S105, S105, S106

Tzfira, T., S135

Uchida, J., S106

Uddin, W., S63, S170, S172

Ueng, P., S106, S159

Ullman, D., S91, S166

Upchurch, R., S114

Uppalapati, S., S106

Uribe, P., S106

Urs, R., S89

Usgaard, T., S162

Ustun, N., S93

Utrillo-Sanchez, B., S152

Vaillancourt, L., S30, S80, S107, S136

Valachovic, Y., S72

Valadez-Moctezuma, E., S97, S151

Valent, B., S9

Valiunas, D., S106, S160, S169

Vallad, G., S106

Valverde, R., S38

van de Werf, W., S52

Van Der Werf, W., S98, S98

van der Westhuizen, L., S88

Van Kan, J., S136

Van Loon, L., S5, S5, S145

van Rij, N., S23

Van, T., S87

Vance, V., S123

Vandemark, G., S56

VandenBosch, K., S162

Vargas, M., S85

Variar, M., S17

Velázquez, K., S154

Venard, C., S107

Venegas, J., S99

Vera Cruz, C., S17, S132

Vick, C., S161

Vidaver, A., S40, S130

Viebahn, M., S5
Viedma, L., S152

Vilchez, M., S46, S110, S110, S110, S154, S154

Villalobos, H., S40

Villalobos-Alcalá, M., S151

Villarreal C., L., S150

Vine, B., S107, S107

Virla, E., S34

Vismer, H., S88

Visser, B., S85

Viterbo, A., S111

Viveros, M., S18, S37

Vlot, A., S55

Voldeng, H., S114

von Broembsen, S., S107, S152

Vossbrinck, C., S169

Vranjic, J., S11, S12

Vurro, M., S126

Wakefield, L., S107

Walcott, R., S17, S29, S29, S50, S129

Waldrop, T., S119

Walker, A., S61

Walker, H., S120

Walker, N., S107, S107

Walkinshaw, C., S108, S176

Wall, G., S152

Walla, J., S108

Wallis, C., S157

Walsh, L., S76

Walters, D., S84

Wamatu, J., S108, S108

Wamishe, Y., S108

Wang, D., S16

Wang, G., S49

Wang, J., S108

Wang, K., S109

Wang, L., S124

Wang, N., S87, S109

Wang, T., S53, S95, S109

Wang, X., S103, S109, S113

Wangdi, T., S40

Wanner, L., S109

Wanyera, R., S49

Warburton, M., S97

Ward, K., S94, S166

Ward, T., S162

Warek, U., S109

Warren, J., S8

Watson, A., S126

Watson, S., S109

Weatherspoon, N., S60

Weaver, G., S146

Weaver, J., S159

Webb, C., S15, S28

Webb, K., S132

Webster, R., S4

Wechter, P., S110

Wedge, D., S2

Wegulo, S., S46, S110, S110, S110, S154, S154

Welacky, T., S59

Weller, D., S4, S11, S145

Wells, L., S39

Weng, Z., S114

Wenner, N., S172

Wenning, B., S65

Wernars, K., S5

Werner, N., S110

West, D., S78

West, L., S46, S110

Westphal, A., S114

Wharton, P., S110, S111, S111

Wheeler, D., S133

Wheeler, T., S21, S41

Wheelis, M., S147

White, D., S108, S111

White, F., S115

Whitfield, A., S166

Whitham, S., S135

Wiangjun, H., S123

Wick, R., S98

Widholm, J., S60

Wiecko, A., S152

Wiersma, J., S43

Wiest, A., S111

Wiggins, B., S135

Wiglesworth, M., S144

Wilcox, W., S33, S118, S143

Willard, B., S122

Williams, L., S118

Williams, R., S66

Williams-Woodward, J., S111, S111

Willie, K., S87

Willocquet, L., S93, S111

Wills, J., Jr., S38, S38

Wilson, A., S112, S112

Wilson, C., S128

Wilson, D., S130

Wilson, L., S128

Windels, C., S13

Windes, J., S112

Windham, A., S112

Windham, M., S60, S60, S61, S61, S112

Wingfield, B., S125

Wingfield, M., S125

Winsor, B., S45

Winston, E., S112

Winters, S., S176

Wise, R., S132

Wiseman, M., S34

Wolf, H., S26

Woloshuk, C., S11, S112

Wolpert, T., S101, S134

Wong, F., S41, S113, S143

Wong, M., S113

Woodward, J., S176

Woodworth, J., S42

Woolfolk, S., S62

Workneh, F., S64, S113

Worley, C., S95

Wright, D., S64, S104

Wright, E., S82

Wu, B., S113

Wu, J., S16, S132

Wu, T., S113

Wyse, D., S164

Xiao, C., S54, S59, S113

Xie, J., S48

Xing, L., S114

Xiong, Z., S2, S114

Xu, H., S114, S114

Xu, J., S54, S166

Xu, J.-R., S124, S163

$\mathrm{Xu}, \mathrm{S} ., \mathrm{S} 55$

Xue, A., S114

Xue, H., S114

Yaganza, E., S173

Yakabe, L., S115

Yamamura, Y., S115, S134

Yan, G., S115

Yandoc, C., S115

Yang, B., S115 
Yang, S., S82, S115, S117

Yang, X., S23, S23, S24, S53, S54, S60, S74, S82, S130, S144, S165

Yang, Y., S55

Yap, M., S82

Yap, M.-N., S133

Ye, W., S141

Ye, X., S71

Yeakley, J., S135

Yegen, O., S116

Yeh, S., S7

Yoder, O., S134

Yokomi, R., S91

Yonce, H., S6

Yorinori, J., S144

Young, G., S116, S167
Young, N., S162

Youssef, S., S95

Ypema, H., S142

Yu, F., S116

Yu, H., S60

Yuan, C., S42

Yuen, G., S116

Yuen, J., S76

Yurgel, S., S94, S94

Zabala, F., S86

Zaitlin, D., S116

Zambino, P., S116, S126

Zanzot, J., S9

Zasada, I., S70, S157, S160

Zelaya-Molina, L., S97

Zeller, K., S15
Zeller, W., S4, S116, S116

Zeng, H., S43

Zeyen, R., S122

Zhang, D., S160

Zhang, J., S36, S116

Zhang, N., S98

Zhang, Q., S115, S117

Zhang, S., S116, S117, S117, S117

Zhang, X., S49, S167

Zhao, B., S137

Zhao, Y., S117, S117, S158, S160, S168

Zheng, F., S43

Zheng, Y., S18

Zhexembekova, M., S134

Zhong, S., S101, S118
Zhou, E., S118

Zhou, J., S45

Zhou, S., S176

Zhou, T., S60

Zhou, X., S118, S160

Zhu, T., S115

Zidack, N., S138

Ziemkiewicz, H., S94

Ziems, A., S93, S118

Zimeri, A., S118

Zindovic, J., S77, S134

Zitomer, N., S173

Zitter, S., S118

Zitter, T., S119

Zummo, N., S152

Zumpetta, C., S38

Zwart, D., S119 